\title{
Observations of Submesoscale Variability and Frontal Subduction within the Mesoscale Eddy Field of the Tasman Sea
}

\author{
Matthew Archer, Amandine Schaeffer, Shane Keating, And Moninya Roughan \\ School of Mathematics and Statistics, University of New South Wales, Sydney, New South Wales, Australia
}

\section{RYAN HOLMES}

School of Mathematics and Statistics, and Climate Change Research Centre, and Centre of Excellence for Climate Extremes, University of New South Wales, Sydney, New South Wales, Australia

\section{LIA SIEGELMAN}

California Institute of Technology, Pasadena, California

(Manuscript received 28 May 2019, in final form 22 March 2020)

\begin{abstract}
Submesoscale lenses of water with anomalous hydrographic properties have previously been observed in the East Australian Current (EAC) system, embedded within the thermocline of mesoscale anticyclonic eddies. The waters within these lenses have high oxygen content and temperature-salinity properties that signify a surface origin. However, it is not known how these lenses form. This study presents field observations that provide insight into a possible generation mechanism via subduction at upper-ocean fronts. Highresolution hydrographic and velocity measurements of submesoscale activity were taken across a front between a mesoscale eddy dipole downstream of the EAC separation point. The front had $O(1)$ Rossby number, strong vertical shear, and flow conducive to symmetric instability. Frontogenesis was measured in conjunction with subduction of an anticyclonic water parcel, indicative of intrathermocline eddy formation. Twenty-five years of satellite imagery reveals the existence of strong mesoscale strain coupled with strong temperature fronts in this region and indicates the conditions that led to frontal subduction observed here are a persistent feature. These processes impact the vertical export of tracers from the surface and dissipation of mesoscale kinetic energy, implicating their importance for understanding regional ocean circulation and biological productivity.
\end{abstract}

\section{Introduction}

Over the past decade, a succession of numerical and observational studies has revealed the rich tapestry of submesoscale ocean currents that have horizontal scales of $O(0.1-10) \mathrm{km}$ and evolve and decay much faster than their mesoscale counterparts [e.g., Capet et al. 2008; Thompson et al. 2016; see McWilliams (2016) for a review]. While submesoscale ocean features were observed several decades earlier (e.g., Flament et al. 1985;

Supplemental information related to this paper is available at the Journals Online website: https://doi.org/10.1175/JPO-D-190131.s1.

Corresponding author: Matthew Archer, matthew.robert.archer@ gmail.com
Munk et al. 2000), it was not until recently that the global extent, complexity, and importance of this scale class has been realized (Mahadevan 2016; Su et al. 2018; Torres et al. 2018). Submesoscales provide a pathway for the cascade of energy from the large scale, where it is input by atmospheric forcing, to the microscale, where it is dissipated, and in modulating the mesoscale field (Molemaker et al. 2010). They are also associated with enhanced turbulence, lateral/vertical mixing, and strong vertical velocities (Klymak et al. 2016; D'Asaro et al. 2011; Shcherbina et al. 2015) and therefore influence primary productivity and atmospheric exchange (Mahadevan 2016; Omand et al. 2015).

Submesoscale currents form through a variety of mechanisms, including mixed layer instabilities (Boccaletti et al. 2007), mesoscale frontogenesis (Spall 1997), and topographic wakes (Molemaker et al. 2015). As such, they 
exhibit strong spatial and temporal inhomogeneity with considerable variation both geographically and seasonally (Sasaki et al. 2014; Callies et al. 2015; Rocha et al. 2016). Difficulties in measuring these intermittent smallscale features have restricted observational studies to a limited number of localized regions, via ship-based field campaigns [e.g., CARTHE (Poje et al. 2014), OSMOSIS (Thompson et al. 2016), SMILES (Adams et al. 2017), LatMix (Shcherbina et al. 2015), repeat ship-of-opportunity sampling (Wang et al. 2010; Qiu et al. 2017; Chereskin et al. 2019), or coast-based high-frequency (HF) radar (Kim et al. 2011; Archer et al. 2015; Schaeffer et al. 2017; Yoo et al. 2018)]. Therefore, many regions of the world remain unsampled with respect to submesoscale ocean variability.

Many of these studies have highlighted the critical role of frontal zones in transferring kinetic and potential energy from the mesoscale current field to submesoscales. Fronts can form by the mesoscale stirring of lateral density gradients; frontogenesis occurs when the density gradients are sharpened through lateral strain. As the front sharpens, an ageostrophic secondary circulation can develop to drive the alongfront flow back to thermal wind balance through restratification (Hoskins 1982). This takes the form of a single overturning cell that can drive vertical exchange between the mixed layer and interior. Submesoscale instabilities can feed off the local potential and kinetic energy of the intensifying front. These instabilities are strongly influenced by the atmosphere-air-sea heat fluxes and frictional wind forcing can both act to further destabilize the water column. The particular flavor of submesoscale instability that dominates is dependent on the distributions of vorticity and density gradients, which can incite gravitational instability (Haine and Marshall 1998), centrifugal/inertial instability (Molemaker et al. 2015), symmetric instability (Thomas et al. 2013), and mixed layer baroclinic instability (Stone 1970; Boccaletti et al. 2007; Fox-Kemper et al. 2008).

During frontal instability, surface water can be subducted along isopycnals, develop anticyclonic vertical vorticity, and separate from the mixed layer to form an intrathermocline eddy (hereafter ITE) [Spall 1995; Thomas 2008; also termed a submesoscale coherent vortex (McWilliams 1985)]. ITEs are submesoscale anticyclonic eddies observed throughout the stratified interior of the ocean (Dugan et al. 1982; Kostianoy and Belkin 1989). They are characterized by their small length scales, well-mixed and anomalous water properties, long lifetimes, and large propagation distances. For these reasons, the cumulative effect of ITEs in the world's oceans has a potentially significant impact on the transport and distribution of heat, salt, and other tracers.
In addition to frontal instability, other mechanisms for ITE generation include bottom drag on boundary currents at topographic features (e.g., D'Asaro 1988; Gula et al. 2019), diapycnal mixing and geostrophic adjustment (e.g., McWilliams 1985), and baroclinic instability of an undercurrent (e.g., Jungclaus 1999). Despite modeling studies that can explain the ITE generation mechanism via frontal instability and subduction (Spall 1995; Thomas 2008), there are few direct observations of this process (Lee et al. 2006). However, such a mechanism may play an important role in ocean-atmosphere exchange, by exporting near-surface water masses influenced by atmospheric forcing down into the ocean interior (Klein and Lapeyre 2009).

In the Tasman Sea east of Australia, Baird and Ridgway (2012, hereafter BR12) identified submesoscale lenses of anomalous water at depth, embedded within mesoscale anticyclonic eddies. The water mass characteristics of these lenses revealed their origin as Bass Strait water, but BR12 did not observe how they form. Brannigan et al. (2017), based on results of high-resolution idealized simulations, conjectured that the Bass Strait lenses observed by BR12 may have formed due to submesoscale instabilities in the mixed layer of mesoscale eddies, but no observations of this process have been made.

Here we present high-resolution in situ observations of submesoscale processes in the Tasman Sea (Fig. 1) taken during a research cruise in austral late winter/early spring 2017. The measurements were made across a frontal zone separating an anticyclonic warm core eddy and cyclonic cold core eddy, immediately south of the East Australian Current (EAC) separation zone (Fig. 1). Our analysis indicates the presence of frontogenesis-induced submesoscale subduction, symmetric instability, and the formation of an intrathermocline eddy. These observations lend support to the theory that such submesoscale lenses may form regularly between mesoscale eddies in the Tasman Sea due to submesoscale instabilities in the mixed layer.

\section{Study region}

Ocean circulation in the Tasman Sea is dominated by the presence of the EAC, the western boundary current (WBC) of the South Pacific subtropical gyre (Suthers et al. 2011; Oke et al. 2019). The EAC is known for being the most variable of WBCs globally, with a large eddy kinetic energy (EKE) to kinetic energy (KE) ratio (Godfrey et al. 1980; Archer et al. 2017). The EAC flows along the continental slope of east Australia until it separates from the coast typically between $30^{\circ}$ and $32^{\circ} \mathrm{S}$ (Cetina-Heredia et al. 2014), flowing eastward as the Tasman Front. At the separation point, mesoscale 

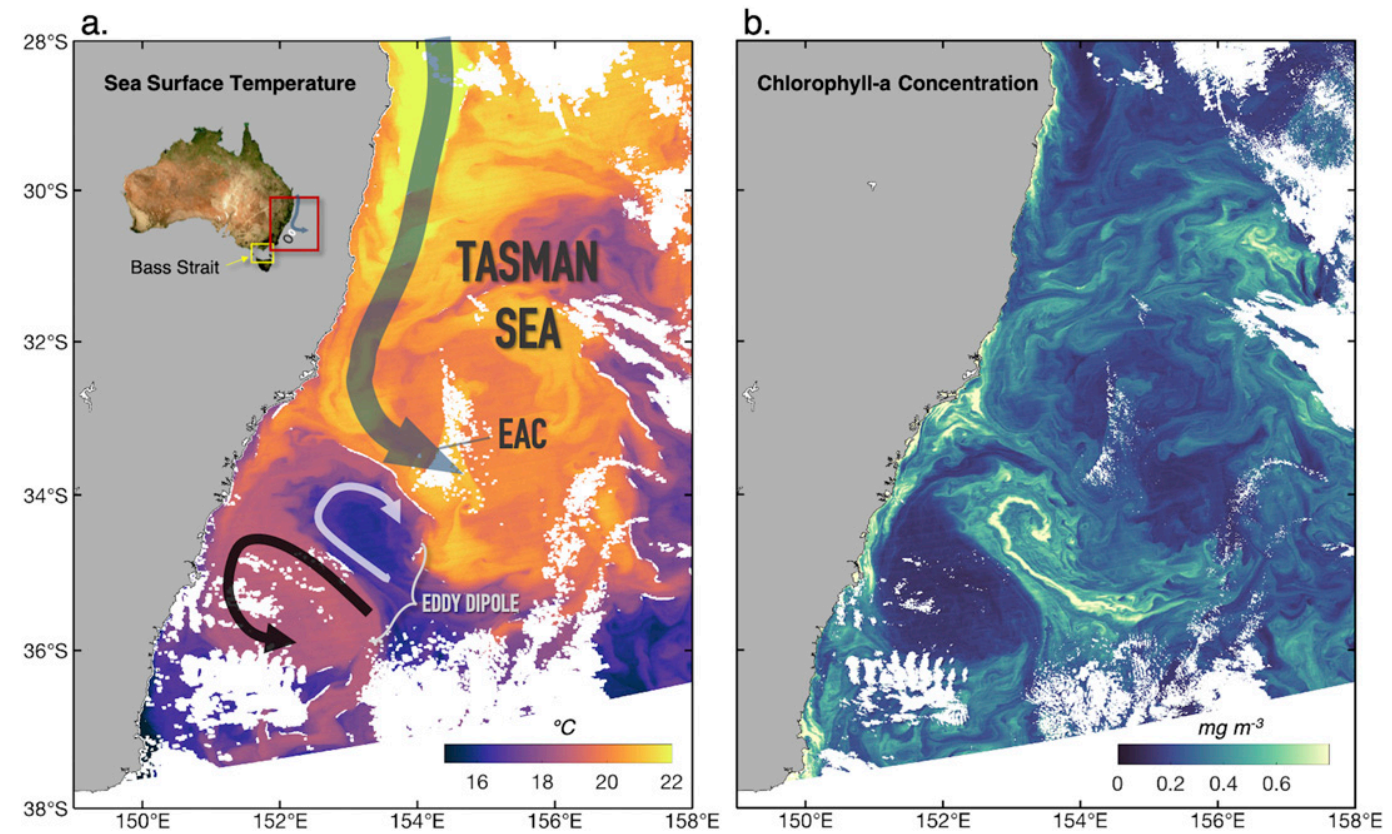

FIG. 1. Satellite imagery in the Tasman Sea reveals the rich submesoscale tapestry of filaments and eddies present around, and within, the mesoscale eddy field: (a) SST $\left({ }^{\circ} \mathrm{C}\right.$ ) and (b) chlorophyll a concentration using the OC3 algorithm $\left(\mathrm{mg} \mathrm{m}^{-3}\right)$. Both datasets are processed to level $\mathrm{L} 2$, with a spatial resolution of $750 \mathrm{~m}$, obtained on 4 Sep 2017 from an ascending swath at approximately 0330 UTC from Suomi-NPP VIIRS. Data source: http:// oceandata.sci.gsfc.nasa.gov. The inset figure in (a) shows the continent of Australia; the red box denotes the study area, and the yellow box denotes Bass Strait, which separates Tasmania from mainland Australia. The East Australian Current (EAC) is denoted by the large gray arrow, and the eddy dipole is denoted with the white (cyclonic eddy) and black (anticyclonic eddy) arrows.

anticyclonic eddies intermittently shed from the EAC retroflection and interact with cyclonic eddies from offshore (Fig. 1). Local wind forcing has been shown to influence the timing of EAC eddy shedding events, whereas remote wind forcing appears to have limited impact on this intrinsically variable WBC system (Bull et al. 2017). The area immediately south of where the EAC separates has been termed "eddy avenue" for its abundance of energetic mesoscale eddies with exceptionally large anomalies in sea surface temperature (SST) and chlorophyll a (Everett et al. 2012). For this reason, the focus of earlier studies in the region was to characterize the variability and dynamics of mesoscale eddies, from a statistical perspective as well as individual case studies (Macdonald et al. 2013; Everett et al. 2015; Roughan et al. 2017; Oke et al. 2019).

Several recent studies have investigated submesoscale variability of the EAC as it flows along the continental shelf upstream of its separation (Roughan et al. 2017; Schaeffer et al. 2017; Mantovanelli et al. 2017; Archer et al. 2018). Submesoscale flow in this regime is characterized by instability of the meandering EAC and generation of frontal eddies (Schaeffer et al. 2017). These eddies have $O(1)$ Rossby number, and asymmetric distributions of vorticity and divergence. They occur intermittently all year round, and are associated with upwelling and elevated chlorophyll a concentrations (Roughan et al. 2017; Schaeffer et al. 2017). Archer et al. (2018) used over 4 years of high-resolution $(1.5 \mathrm{~km}) \mathrm{HF}$ radar observations in this upstream region to explore surface current variability; in EKE wavenumber spectra they identified a $k^{-3}$ power spectral slope, which indicates the dominance of mesoscale motions, and little-to-no seasonality in submesoscale variance. Poleward of where the EAC separates from the coast, satellite imagery reveals submesoscale features (Fig. 1), yet there have been no dedicated in situ observations to determine the subsurface hydrographic and velocity structure of these scales. The measurements analyzed here are the first to focus on these upper-ocean submesoscales poleward of the EAC separation.

\section{Data and methods}

\section{a. Shipboard observations}

The primary observations used in this study were collected during a research cruise in the Tasman Sea, 
austral late winter/early spring (31 August- 18 September 2017), aboard the R/V Investigator (Malan et al. 2020). Standard shipboard underway measurements used include salinity and temperature from a thermosalinograph (Sea-Bird SBE 21) with measurement depth of $2 \mathrm{~m}$ within the drop keel, and wind speed and direction from a wind vane (RM Young Wind Sensor Type 05108) on the starboard foremast. Vertical profiles of conductivity (SBE4C), temperature (SBE3T), pressure, and dissolved oxygen (DO; SBE43) were made by a Sea-Bird SBE 911, down to a depth of $1000 \mathrm{~m}$ at 1 dbar intervals. The voyage data are quality controlled by the Australian Marine National Facility staff using their standard procedures (https://doi.org/10.4225/08/ 5a964b9041903). Potential density, Absolute Salinity, Conservative Temperature, and the thermal expansion coefficient were calculated using the TEOS-10 toolbox (McDougall and Barker 2011).

Vertical profiles of horizontal currents were collected down to a depth of $\sim 800 \mathrm{~m}$ with $8-\mathrm{m}$ vertical bins and 1.2-km horizontal spacing, using a ship-mounted acoustic Doppler current meter (S-ADCP; RDI OS $75-\mathrm{kHz}$ narrowband operation). The University of Hawaii's Common Ocean Data Access System (CODAS) was used for postprocessing, including corrections for ship speed and heading, with data output as $5 \mathrm{~min}$ averages from $1-\mathrm{Hz}$ sampling frequency. Unless otherwise stated, all velocity is rotated to along the ship track ( $u$ component) and across track ( $v$ component), which is approximately equivalent to being across front $(u)$ and alongfront $(v)$, since the ship passed the frontal zone almost perpendicular to its axis (within $4^{\circ}$ ). We tested the sensitivity of our results to this rotation angle, comparing velocity data rotated to the surface front velocity orientation as well as the 200-m depth-averaged front orientation; the results are not sensitive to these changes.

A Triaxus (a vertically profiling towed body) was deployed to map the hydrographic structure across the front at high resolution (at 1446-2227 UTC 12 September). It was equipped with a dual-sensor Seabird SBE 911, collecting temperature, conductivity, pressure, and DO. Chlorophyll was measured by an Eco-Triplet payload. The Triaxus was towed at a speed of $8 \mathrm{kt}\left(\sim 4 \mathrm{~m} \mathrm{~s}^{-1}\right)$, approximately $1.5 \mathrm{~km}$ behind the vessel, in a sawtooth pattern with horizontal spacing of $\sim 2 \mathrm{~km}$ between bottom turns, over vertical dives of $\sim 200 \mathrm{~m}$. This equates to a time lag between the S-ADCP and Triaxus measurements of approximately $6 \mathrm{~min}$. The depth of the dives was progressively increased throughout the deployment to capture the base of the mixed layer, as the ship moved from the cold core eddy to the warm core eddy. All Triaxus-measured variables are gridded horizontally $(d x \sim 1 \mathrm{~km})$ and vertically $(d z=1 \mathrm{~m})$ by linearly interpolating between successive up- and downcasts.

\section{b. Satellite imagery}

To characterize the mesoscale eddy field, we use satellite-measured absolute dynamic topography (ADT) and geostrophic currents obtained from the DUACSDT2014 L4 gridded multimission altimeter daily product on a $0.25^{\circ} \times 0.25^{\circ}$ resolution grid (Pujol et al. 2016). Backward-in-time finite-size Lyapunov exponents (FSLE; day $^{-1}$ ) are supplied by AVISO at a horizontal resolution of $0.04^{\circ}$, calculated from geostrophic velocities. FSLEs are a Lagrangian diagnostic measuring the exponential rate of separation $\lambda$ between two neighboring particles during a time of advection $t$, defined as $\lambda=t^{-1} \log \left(\delta_{0} / \delta_{f}\right)$, where $\delta_{0}\left(\delta_{f}\right)$ is the initial (final) separation distance (d'Ovidio et al. 2004). AVISO-defined parameters are $\delta_{0}=0.02^{\circ}$ and $\delta_{f}=$ $0.6^{\circ}$, with a maximum integration window of 200 days. FSLEs are used here to diagnose the strain field (Waugh and Abraham 2008) and are positively correlated with gradients of buoyancy at the submesoscale, as shown in the Antarctic Circumpolar Current (ACC) (Siegelman et al. 2020). Since we use several satellite SST and chlorophyll a datasets, we note the data source when used in the text.

\section{c. Diagnostic calculations}

The satellite data are on a Cartesian longitudelatitude grid, so we calculate both horizontal gradient terms $(\partial / \partial x$ and $\partial / \partial y)$. However, for in situ measurements, horizontal gradients can only be calculated along the ship track. Therefore, we orientate the coordinate system along track ( $x$ direction) and across track ( $y$ direction), and assume that across-front gradients $(\partial / \partial x)$ are significantly larger than alongfront gradients $(\partial / \partial y \rightarrow 0)$, which is a reasonable approximation based on the high-resolution SST imagery depicting a nearly straight front during the in situ sampling (see section 5). The $z$ coordinate is positive upward. We calculate all gradients using a centered second-order differencing scheme.

\section{1) IN SITU VELOCITY GRADIENT TENSOR}

From the horizontal velocity gradient tensor, we calculate vertical relative vorticity

$$
\zeta=\frac{\partial v}{\partial x}
$$

horizontal divergence

$$
\delta=\frac{\partial u}{\partial x}
$$


and strain

$$
\sigma=\left[\left(\frac{\partial u}{\partial x}\right)^{2}+\left(\frac{\partial v}{\partial x}\right)^{2}\right]^{1 / 2}
$$

\section{2) IN SITU POTENTIAL VORTICITY CALCULATION}

Ertel potential vorticity (hereafter PV, or denoted by the symbol $q$ ) can be used as a diagnostic to indicate the susceptibility of the flow to instability (e.g., Hoskins 1974; Thomas et al. 2008). In its full form it is

$$
q=(f+\nabla \times \mathbf{u}) \cdot \nabla b,
$$

where $\mathbf{u}=(u, v, w)$ is the velocity vector, $f$ is the Coriolis parameter, and $b=-g \rho^{\prime} / \rho_{0}$ is the buoyancy ( $g$ is acceleration due to gravity, $\rho^{\prime}$ is a density perturbation, and $\rho_{0}$ is a reference density, taken here as the full-depth mean). When PV has the opposite sign of $f(f q<0)$, the flow is inherently unstable (Thomas et al. 2013). PV can be decomposed into two main terms:

$$
\begin{aligned}
q & =q_{\mathrm{vert}}+q_{\mathrm{bc}}, \\
q_{\mathrm{vert}} & =(f+\zeta) N^{2}, \quad \text { and } \\
q_{\mathrm{bc}} & =\left(-\frac{\partial v}{\partial z}\right) \frac{\partial b}{\partial x}=-\frac{\partial v}{\partial z} M^{2},
\end{aligned}
$$

where $N^{2}=\partial b / \partial z$ is the vertical buoyancy gradient, and $M^{2}=\partial b / \partial x$ is the horizontal buoyancy gradient. The term $q_{\text {vert }}$ relates to the vertical component of absolute vorticity $(f+\zeta)$ and $N^{2}$, and $q_{\text {bc }}$ relates to the horizontal relative vorticity (vertical shear) and $M^{2}$. Gravitational instability can occur when $N^{2}<0$. If the water column is stably stratified $\left(N^{2}>0\right)$ then for $f q_{\text {vert }}<0$, inertial or centrifugal instability may occur. However, if $f q<0$ is due to the baroclinic term, $f q_{\mathrm{bc}}<0$, then symmetric instability can occur (Thomas et al. 2013). When the frontal flow is approximately in thermal wind balance (i.e., the vertical shear is geostrophic $\partial v_{g} / \partial z=1 / f(\partial b / \partial x)$, $q_{\mathrm{bc}}$ can be expressed as (Thomas et al. 2008)

$$
q_{\mathrm{bc}}^{g}=-f\left(\frac{\partial v_{g}}{\partial z}\right)^{2}=-\frac{1}{f}\left(\frac{\partial b}{\partial x}\right)^{2}=-\frac{M^{4}}{f} .
$$

Thus $f q_{\mathrm{bc}}^{g}$ is a negative definite quantity so that the baroclinicity of the thermal wind shear always acts toward $f q<0$ (i.e., the horizontal vorticity of the geostrophic shear is "anticyclonic"). Therefore, symmetric instability can occur when the magnitude of $q_{\mathrm{bc}}^{g}$ exceeds $q_{\mathrm{vert}}$. To incorporate the effect of flow curvature, we calculate PV in cylindrical coordinates (Shakespeare 2016):

$$
q_{\mathrm{cyl}}=\left(f+\frac{\partial v_{\theta}}{\partial r}+\frac{v_{\theta}}{R}\right) \frac{\partial b}{\partial z}-\frac{1}{f}\left(\frac{\partial b}{\partial r}\right)^{2}
$$

where $v_{\theta}$ is the radial velocity, $r$ is the radial coordinate, and $R$ is the radius of curvature.

\section{3) ATMOSPHERIC FORCING}

Frictional forces associated with wind forcing over an ocean front can modulate the PV (and so potentially drive instability) as captured by the Ekman buoyancy flux:

$$
\mathrm{EBF}=\left.\frac{\tau_{y}}{\rho_{0} f} \frac{\partial b}{\partial x}\right|_{z=0},
$$

where $\tau_{y}$ is the alongfront component of the wind stress. Winds directed along the front in the direction of the thermal wind shear (i.e., downfront, EBF $>0$ ) will drive a frictional Ekman transport that forces dense water over light, acting to steepen the front and reduce the vertical stratification (Thomas and Lee 2005), injecting positive PV (in the Southern Hemisphere) into the ocean, encouraging $f q<0$. The interaction of wind stress with the relative vorticity of the ocean front can also induce Ekman convergence/divergence and drive vertical motions (Thomas and Lee 2005). Thus, independent of any air-sea heat and salt fluxes, downfront winds are destabilizing. For comparison with previous studies, we convert EBF into an equivalent heat flux (e.g., Thompson et al. 2016):

$$
Q_{\mathrm{EK}}=-\frac{\rho_{0} C_{p}}{\alpha g} \mathrm{EBF},
$$

where $C_{p}$ is the specific heat of seawater (taken here as $3992 \mathrm{~J} \mathrm{~kg}^{-1}{ }^{\circ} \mathrm{C}^{-1}$ ), and $\alpha$ is the thermal expansion coefficient, a function of salinity and temperature. EBF used here is calculated using the 2-m density gradient derived from the underway measurements. A negative $Q_{\text {EK }}$ (associated with downfront winds, EBF $>0$ ) destabilizes the mixed layer.

The total air-sea heat flux is $Q_{\mathrm{HF}}=Q_{\text {shortwave }}+$ $Q_{\text {longwave }}+Q_{\text {latent }}+Q_{\text {sensible }}+Q_{\text {rain }}\left(\mathrm{Wm}^{-2}\right)$. The term $Q_{\mathrm{HF}}$ is calculated from shipboard meteorological and oceanographic observations using the COARE 3.0a bulk algorithms (Fairall et al. 1996). When $Q_{\mathrm{HF}}$ is positive (negative), the ocean gains (loses) heat, stabilizing (destabilizing) the water column.

\section{4) Frontogenesis}

The frontogenesis function provides a measure of the rate at which horizontal velocity gradients can increase the lateral buoyancy gradient (Hoskins 1982), 


$$
F=2\left(-\frac{\partial u}{\partial x} \frac{\partial b}{\partial x}\right) \frac{\partial b}{\partial x}
$$

where $F$ is one term in the equation for the Lagrangian evolution of the horizontal buoyancy gradient (Holmes et al. 2014) $(D / D t)|\partial b / \partial x|^{2}$ and is calculated using the Triaxus-measured buoyancy gradient and ADCP-measured velocity (Thomas et al. 2013). Parameter $F>0$ indicates that horizontal strain is acting to drive frontogenesis. Typically, this will induce an ageostrophic secondary circulation that partially balances the frontogenetic tendency (through differential vertical advection; Hoskins 1982).

\section{d. Data processing}

\section{1) Collocating in Situ datasets}

To calculate specific terms (see section 3c), the hydrographic and velocity observations need to be collocated. ADCP-measured velocity and its vertical/horizontal shear is linearly interpolated from its native grid to the Triaxus grid in $x / z$ coordinates. The final dataset has a resolution of $1 \mathrm{~m}$ in the vertical and $\sim 1 \mathrm{~km}$ along track. We also tested interpolating from the Triaxus to ADCP grid, with the same results. Horizontal and vertical gradients in all properties are computed via central differencing.

\section{2) CAlculating ERror BARS}

To evaluate the significance of the PV field, given the limited observations available, we run a Monte Carlo experiment using error estimates of velocity $\left(5 \mathrm{~cm} \mathrm{~s}^{-1}\right)$, temperature $\left(0.002^{\circ} \mathrm{C}\right)$ and salinity $(0.005 \mathrm{psu})$. These estimates are twice the manufacturer-supplied accuracy for temperature and salinity, and twice the error found in an empirical study of the RDI S-ADCP accuracy (Fischer et al. 2003). We assume Gaussian error distributions with zero mean and STD equal to the estimated error, then randomly assign these errors to each grid point. From these new noisy fields, we calculate gradients and the terms described in section $3 \mathrm{c}$; then repeat 1000 times. From these one thousand realizations, we derive confidence intervals based on the Student's $t$ distribution, assuming a sample STD (unknown population STD), with $N-1$ degrees of freedom.

\section{Mesoscale eddy field (austral winter 2017)}

\section{a. EAC eddy shedding event}

During August and September 2017, satellite ADT maps reveal an EAC anticyclonic eddy shedding and reattachment event at approximately $34^{\circ} \mathrm{S}$ (Fig. 2). The anticyclonic eddy shedding was associated with an offshore cyclonic eddy that propagated westward. As the anticyclonic eddy detached from the EAC jet (1-10 August), the cyclonic eddy squeezed in between the two warm water masses, thus forming an eddy dipole with the anticyclone, southwest of the EAC jet separation [see Malan et al. (2020) for details on the eddy-driven cross-shelf transport of this dipole]. Over this period the anticyclonic eddy slowly decayed, with decreasing ADT amplitude and spatial scale. The cyclonic eddy also shrunk as it moved westward and became constrained between the EAC and anticyclonic eddy. Toward the end of September, the cyclonic eddy was squeezed out to the south as the anticyclonic eddy reconnected with the EAC jet (Figs. 2 and 3).

\section{b. Mesoscale frontal structure}

The evolution of the eddy dipole generated strong fronts that divided the distinct water masses of the warm EAC, cold cyclonic eddy, and warm anticyclonic eddy (Fig. 3a). The fronts exhibit large gradients in SST over short distances (with a negative gradient within the eddy dipole $\sim 34^{\circ}-35^{\circ} \mathrm{S}$; Fig. $3 b$ ). The time-latitude Hovmöller plot of FSLE (Fig. 3c) shows the evolution over a 2-month period. FSLEs reach values of up to 1 day $^{-1}$, characteristic of an intense strain field and similar to values found in the ACC (Siegelman et al. 2020). As the cyclonic eddy moved westward between the EAC and the anticyclonic eddy, strain increased, and FSLE values between the two eddies were intensifying as the ship passes the front. This indicates the front is undergoing frontogenesis.

High-resolution SST imagery of the front on the day of sampling shows it to have slight anticyclonic curvature (Figs. 4a,b). To calculate the radius of curvature $R$, we best fit a circle to this frontal region, obtaining $R=$ $80 \mathrm{~km}$. The cyclogeostrophic Rossby number, $C=v_{\theta} / f R$, provides a metric of the influence of curvature on the flow (Shakespeare 2016). Based on a depth-averaged $v_{\theta}$ at the front, and the $R$ calculated above, we obtain $C=-0.14$, which is relatively low and indicates a weak influence. The negative value is due to anticyclonic curvature and implies an increase in $v_{\theta}$ for the forces to remain in balance (horizontal pressure gradient, Coriolis, and centripetal).

At the time of in situ sampling, the ADT-derived geostrophic speed of the onshore jet of the dipole reached a maximum of $1.3 \mathrm{~m} \mathrm{~s}^{-1}$ (Fig. 4f). The geostrophic vorticity (normalized by $|f|$ ) measured nearest the front reached $-0.15 f$, while the anticyclonic vorticity was $0.08 f$. Within the eddy cores, vorticity values peaked at $-0.4 f$ and $0.3 f$, respectively, indicating relatively high 

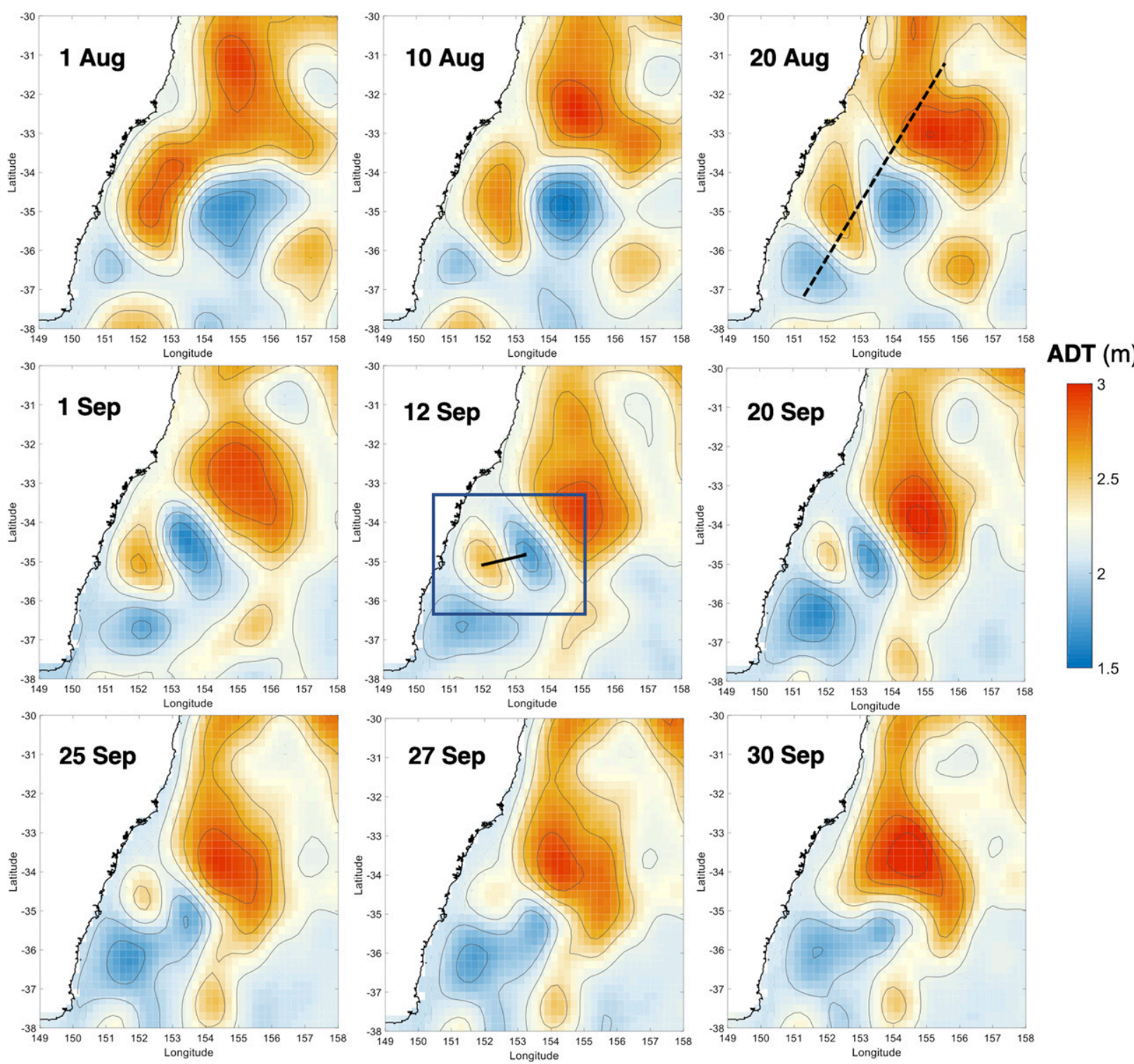

FIG. 2. Evolution of the EAC eddy shedding event shown in nine snapshots of absolute dynamic topography (ADT), starting 1 Aug when an anticyclonic eddy was shed from the EAC through to 30 Sep, when the same feature reattached to the EAC. On 12 Sep, in situ measurements were taken along the ship transect denoted by the black line. The eddy dipole feature is encased within the blue box. The black dashed line in the top-right figure denotes the transect over which the Hovmöllers in Fig. 3 are plotted.

mesoscale Rossby numbers. Even though these geostrophic measurements reveal an energetic mesoscale field, the in situ observations presented next reveal much larger values of velocity and its spatial gradients at the submesoscale range.

\section{Submesoscale processes at the front}

\section{a. Submesoscale frontal structure}

In situ measurements augment the large-scale view of the eddy dipole from satellite ADT observations, revealing submesoscale characteristics embedded within the mesoscale field (e.g., Fig. 4g). At the shallowest ADCP bin (centered at $28 \mathrm{~m}$ ), the velocity of the jet core is $1.85 \mathrm{~m} \mathrm{~s}^{-1}$, with asymmetric lateral shear across the front. The cyclonic shear on the cold eastern side of the jet, measured as $d v / d x$, has a maximum of $2.3 f$. Conversely, the anticyclonic shear flank of the jet peaks at $-0.76 f$, as it is constrained from exceeding $f$ (Shcherbina et al. 2013; Thomas et al. 2008). In contrast, the satellite-derived vorticity reaches a peak magnitude of $0.4 f$. The difference between satellite-measured geostrophic and in situ velocities reveals that while the satellite observations do a good job of representing the 

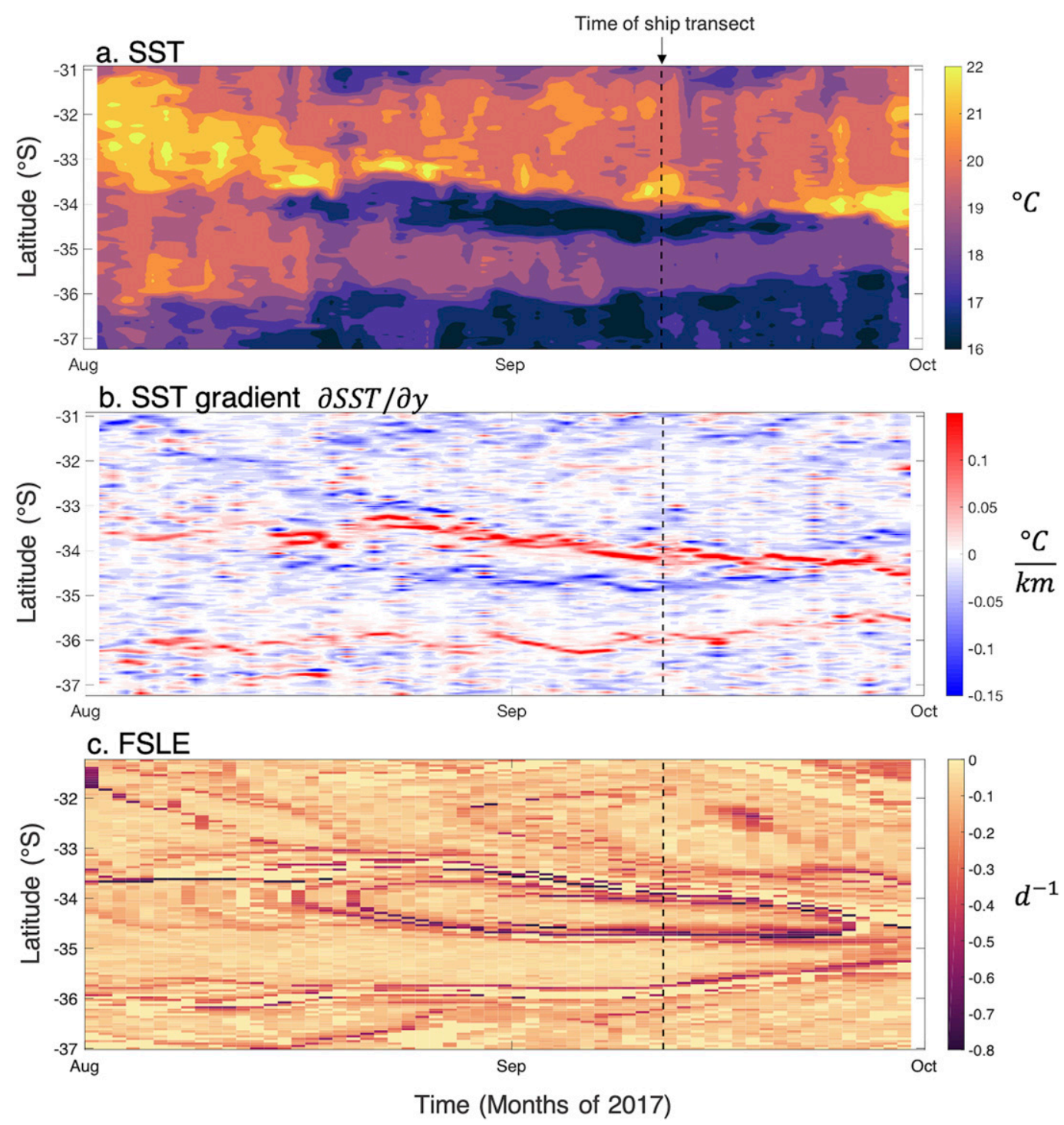

FIG. 3. Time-latitude Hovmöllers along a transect shown in Fig. 2 during August-September reveal the evolution of (a) SST; (b) along-transect gradient in SST, which highlights the thermal fronts between the eddies and the EAC; and (c) FSLE $\left(\right.$ day $\left.^{-1}\right)$, which characterizes the strain field over time. The black dashed line denotes the 12 Sep when the in situ measurements were taken. For consistency and time coverage, the SST used here is the objectively analyzed daily blended L4 SST 1-km resolution product (PO.DAAC g1sst product: https://podaac-opendap.jpl.nasa.gov/).

mesoscale, finescale structure at the front is not captured by altimetry.

Based on a high-resolution vertical slice from the Triaxus, the front has a width of $\sim 15 \mathrm{~km}$, and extends down to 200-m depth (Fig. 5). The mixed layer base ascends from $\sim 275$ to $\sim 175 \mathrm{~m}$ over a range of $60 \mathrm{~km}$. The front is demarcated by exceptionally strong horizontal gradients in all measured properties, with warmer, saltier, low-oxygen content water in the deeper mixed layer of the anticyclonic eddy, and colder, fresher, high-oxygen content in the cyclonic eddy. There is a significantly higher concentration of chlorophyll a in the cyclonic eddy (Fig. 5f). The front tilts with depth in the direction of the anticyclonic eddy. Below the isopycnal outcrop the weakly stratified, cold and fresh surface water of the cyclonic eddy appears to subduct into the pycnocline (e.g., Fig. 5c). Undulating isopycnals at the base of the mixed layer are the signatures of internal gravity waves with amplitudes as large as $50 \mathrm{~m}$ and wavelengths $\sim 15 \mathrm{~km}$ (if observations can be assumed near-instantaneous with respect to the propagating internal waves), and their impact is seen on all variables, particularly chlorophyll a and oxygen (Figs. 5c,f). Without additional information 

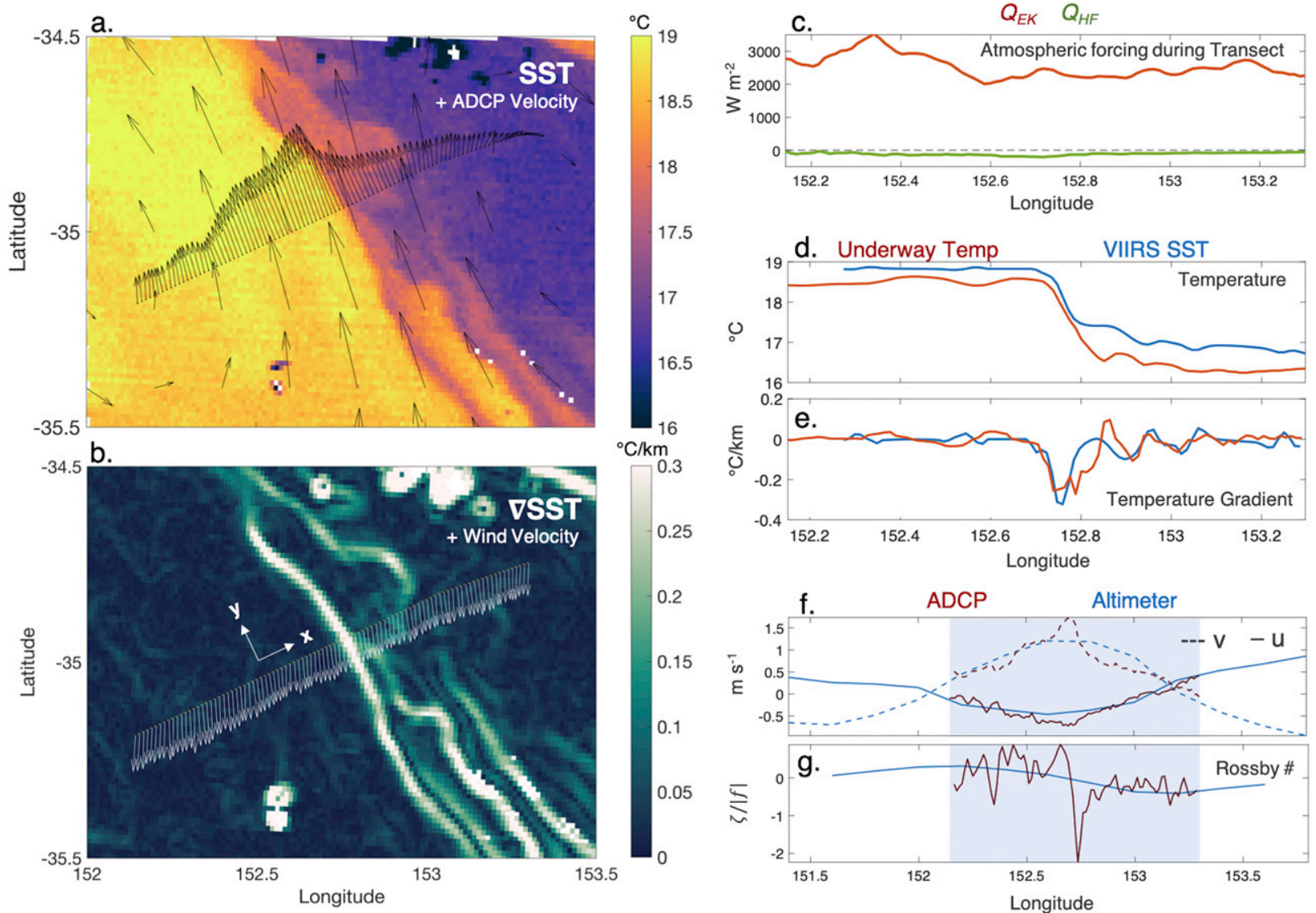

FIG. 4. (a) A VIIRS L2 swath measurement of SST at $~ 1542$ UTC 12 Sep, the day the ship transected the front. The black arrows show ADCP-derived horizontal currents at $28 \mathrm{~m}$. (b) The horizontal gradient of the SST field. The white arrows show shipboard-measured wind velocity, which is upfront at this time. The local Cartesian coordinates used to calculate derivates is shown. (c) Atmospheric forcing during in situ sampling; the total heat flux $Q_{\mathrm{HF}}$ (negative indicates the ocean loses heat) and Ekman equivalent heat flux $Q_{\mathrm{EQ}}$ (positive indicates upfront winds with a stabilizing influence). (d) In situ underway temperature measurement at $2 \mathrm{~m}$ and the SST interpolated onto the transect. (e) The along-transect gradient of the underway temperature and VIIRS SST. (f) Meridional $v$ and zonal $u$ velocity components. (g) Relative vorticity normalized by $|f|$, for ADCP-derived currents (red), and ADT-derived geostrophic currents interpolated onto the transect (blue). (SST data source: http://oceandata.sci.gsfc.nasa.gov).

it is not clear whether these waves were generated remotely or by the front itself (e.g., Shakespeare and Taylor 2014).

The S-ADCP vertical profiles of the horizontal currents reveal the outcropping isopycnals are associated with strong alongfront velocity, greater than $1 \mathrm{~m} \mathrm{~s}^{-1}$ all the way down to the base of the mixed layer (Fig. 6a). This velocity has significant vertical shear (Figs. 6c,f), and is primarily in thermal wind balance along the front until the base of the mixed layer, as shown in Fig. 7b, where the departure from thermal wind balance is shown (in \%) (Holmes et al. 2014):

$$
\gamma_{\text {TWB }}=\frac{\left|\frac{d v}{d z}-\frac{d v_{g}}{d z}\right|}{\left|\frac{d v}{d z}\right|+\left|\frac{d v_{g}}{d z}\right|} \times 100 .
$$

Outside of the narrow front, the weaker shear is predominantly ageostrophic with large $\gamma_{\mathrm{TWB}}$. Such differences are expected in the mixed layer and pycnocline where internal waves are evident, but not the ageostrophic shear at the base of the front at 250-m depth, $40 \mathrm{~km}$ along track (Fig. 6f); in the same region the across-front velocity is large $\left(\sim 25 \mathrm{~cm} \mathrm{~s}^{-1}\right)$ and indicates the water moving in the direction of the warm core eddy (Fig. 6b). The relative vorticity is asymmetric and dominated by the cyclonic component along the front, and coincident with high strain values, typical of submesoscale motions (Figs. 6d,e) (Mahadevan 2016).

The magnitude of horizontal buoyancy gradient $M^{2}$ at the front is $\sim 6 \times 10^{-7} \mathrm{~s}^{-2}$ (Fig. 5e). This is very high, and comparable to strong fronts measured elsewhere [in the ACC, Adams et al. (2017); in the Kuroshio, D'Asaro et al. (2011)]. From 4 months of glider measurements in the 

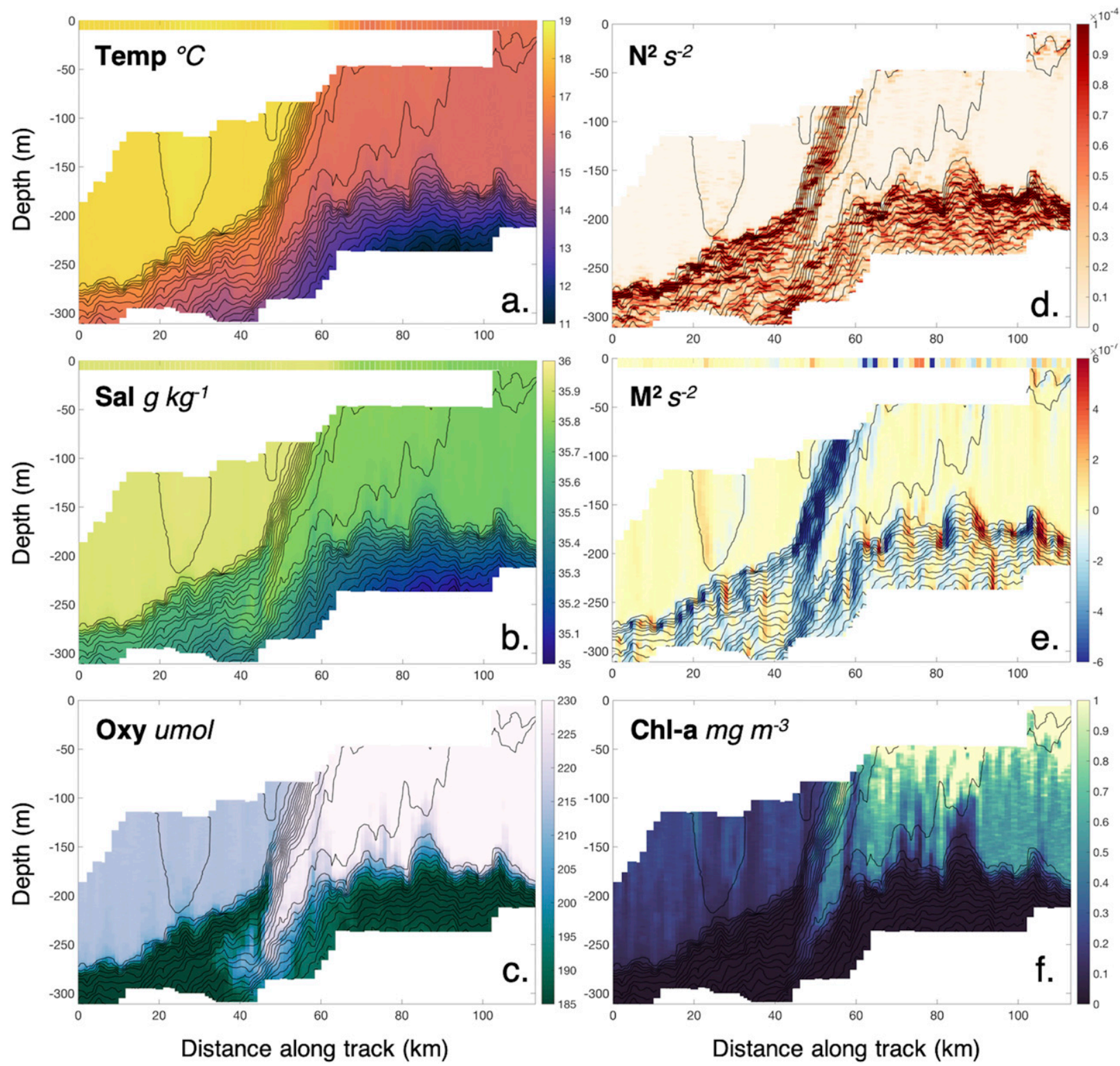

FIG. 5. Cross-front ( $x-z$ plane) sections measured by the Triaxus: (a) Conservative Temperature $\left({ }^{\circ} \mathrm{C}\right),(\mathrm{b}) \mathrm{Absolute}$ Salinity $\left(\mathrm{g} \mathrm{kg}{ }^{-1}\right)$, and (c) dissolved oxygen $(\mu \mathrm{mol})$. Derived variables are (d) $N^{2}$ the Brunt-Väisälä frequency $\left(\mathrm{s}^{-2}\right)$, (e) $M^{2}$ the horizontal density gradient $\left(\mathrm{s}^{-2}\right.$; note $f^{-1} M^{2}$ is thermal wind balance), and (f) chlorophyll a $\left(\mathrm{mg} \mathrm{m}^{-3}\right.$, as derived from fluorescence). Line contours represent potential density referenced to the surface, from 1025.7 to $1026.7 \mathrm{~kg} \mathrm{~m}^{-3}$ in intervals of $0.035 \mathrm{~kg} \mathrm{~m}^{-3}$. In (a), (b), and (e), data from the underway thermosalinograph at 2-m depth has been plotted.

ACC, Viglione et al. (2018) found $M^{2}$ magnitudes exceeded $6 \times 10^{-7} \mathrm{~s}^{-2}$ less than $1 \%$ of the time (although this estimate is conservative given their $5-\mathrm{km}$ sampling resolution and assuming the glider rarely sampled exactly perpendicular to fronts). When we calculate $M^{2}$ at 2-m depth using thermosalinograph measurements with a 5 -min sampling rate and a mean spatial resolution of $1 \mathrm{~km}$, we obtain an even greater value of $1 \times 10^{-6} \mathrm{~s}^{-2}$ (Fig. 5e).

The frontogenesis function has values of $2.5 \times$ $10^{-17} \mathrm{~s}^{-5}$ (Fig. 7a), coincident with the altimetry- derived strain rate increase at this time (Fig. 3c). Note in our calculation we use the full velocity rather than the geostrophic component, which may include strain from other sources, such as internal waves. However, similar values can be obtained by taking the ADT-derived geostrophic strain $(\sim 0.4 f)$ and average $M^{2}$ at the front $\left(\sim 5 \times 10^{-7} \mathrm{~s}^{-2}\right)$, giving $F=1.7 \times$ $10^{-17} \mathrm{~s}^{-5}$. This indicates horizontal strain is acting to increase the horizontal density gradient of the front, reaching a similar magnitude to that observed at a Gulf 

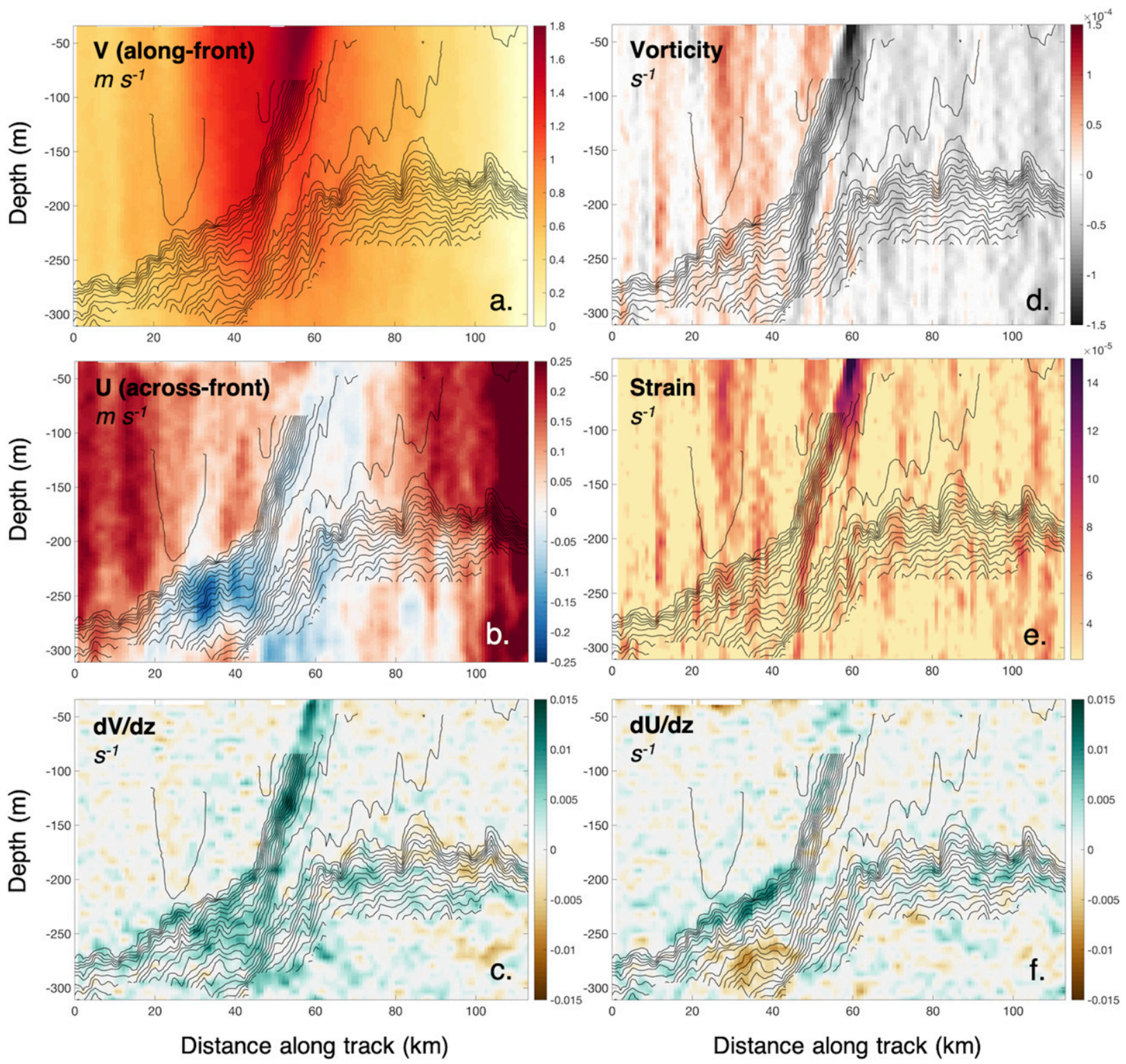

FIG. 6. Cross-front ( $x-z$ plane) sections measured by the shipboard ADCP: (a) alongfront velocity ( $\mathrm{m} \mathrm{s}^{-1}$ ), (b) across-front velocity $\left(\mathrm{m} \mathrm{s}^{-1}\right),(\mathrm{c})$ vertical shear of alongfront velocity $\left(\mathrm{s}^{-1}\right),(\mathrm{d})$ vertical relative vorticity $\left(\mathrm{s}^{-1}\right),(\mathrm{e})$ strain, and (f) vertical shear of across-front velocity $\left(\mathrm{s}^{-1}\right)$. Line contours represent potential density referenced to the surface, from 1025.7 to $1026.7 \mathrm{~kg} \mathrm{~m}^{-3}$ in intervals of $0.035 \mathrm{~kg} \mathrm{~m}^{-3}$.

Stream front in Thomas et al. (2013). Fluid parcels being carried along the front in the confluent region must accelerate to remain in cross-frontal geostrophic balance. According to the semigeostrophic momentum balance such an acceleration is balanced by an ageostrophic secondary circulation (ASC; Hoskins 1982). This ageostrophic flow will tend to subduct water below the front from the cold cyclonic side (e.g., see Fig. 12 of Pollard and Regier 1992). At the base of the front, there is a region of frontolysis in proximity to the subducting water parcel, associated with slightly divergent flow. This process has been noted by
Holmes et al. (2014) near the equator-convergence of water at an upper-ocean front drives subduction of water, which feeds divergent flow at depth that can lead to frontolysis (although alongfront convergence/divergence can also absorb this subducting flow).

\section{b. Subduction}

Subduction of water appears to be occurring at 200-m depth, $55 \mathrm{~km}$ along track (Figs. 5-8). This is a region of anticyclonic vorticity (Fig. 6d), which leads to near-zero absolute vorticity (defined here as $\zeta_{a}=f+\partial v / \partial x$ ) in this 

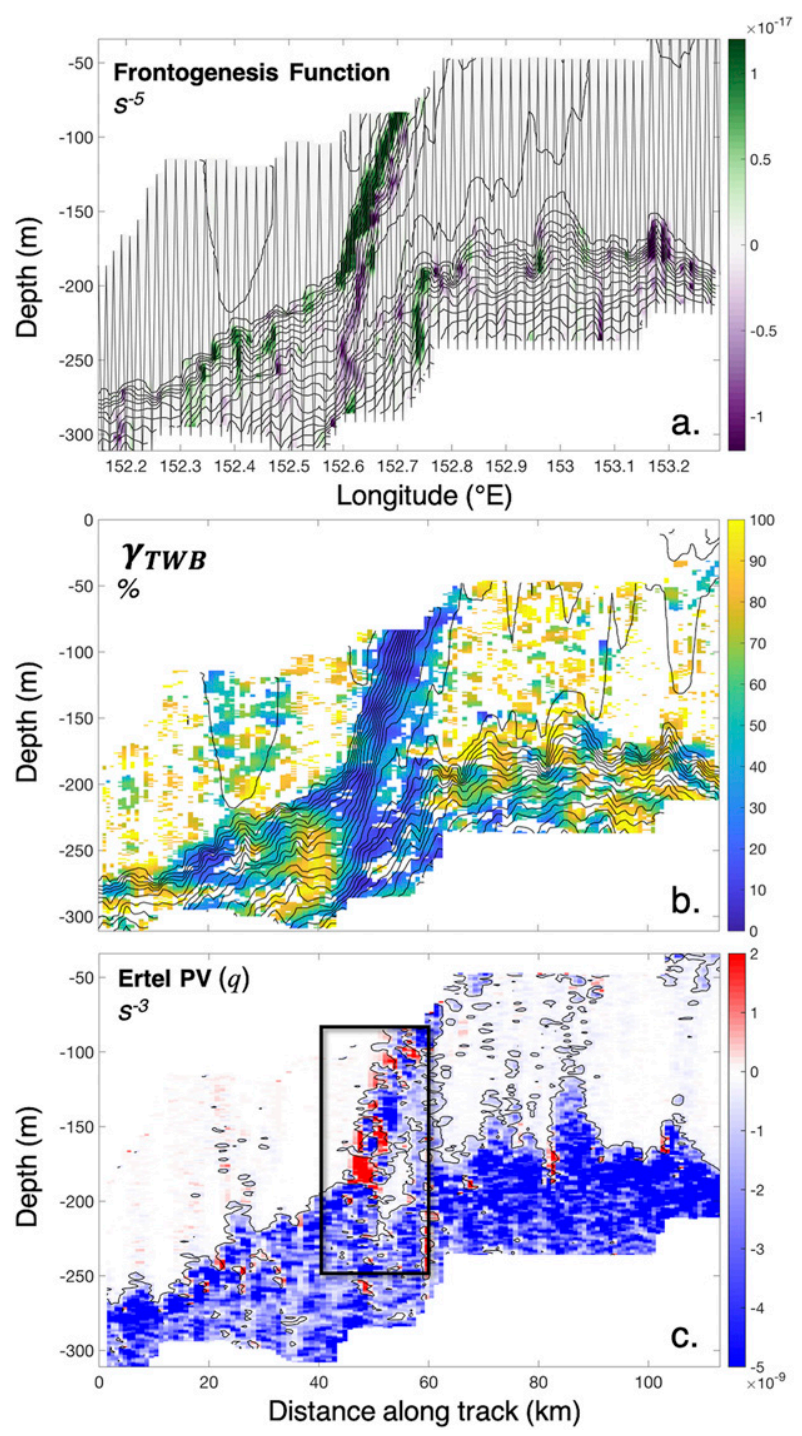

FIG. 7. Cross-front ( $x-z$ plane) sections of variables derived from both hydrographic and velocity measurements. (a) Frontogenesis function, superimposed in gray lines is the Triaxus profile track. (b) Percent error of thermal wind balance $\gamma_{\mathrm{TWB}}$; if the flow is in perfect thermal wind balance, $\gamma_{\mathrm{TWB}}$ will be zero. Cells not statistically significant have been blanked out. (c) Ertel potential vorticity $q$. In (a) and (b), line contours represent potential density referenced to the surface, from 1025.7 to $1026.7 \mathrm{~kg} \mathrm{~m}^{-3}$ in intervals of $0.035 \mathrm{~kg} \mathrm{~m}^{-3}$. In (c), line contours represent the mixed layer $\mathrm{PV}=5 \times 10^{-10} \mathrm{~s}^{-3}$. The black box denotes the zoomed-in region shown in Fig. 8.

water parcel as $f \approx-8 \times 10^{-5} \mathrm{~s}^{-1}$. This water parcel also exhibits low stratification, low-magnitude PV (Fig. 7c), and is associated with high oxygen and chlorophyll a content (Figs. 5c,f). The low-magnitude PV water parcel is separated from the mixed layer by a band of negative PV (i.e., white parcel in Fig. 7c). This is characteristic of the formation mechanism of ITEs, as shown in the simulations of Spall (1995) and Thomas (2008). Their simulations show that ITEs can evolve from subducted water, which separates from the mixed layer and moves into the thermocline, with anticyclonic vorticity, low-magnitude PV, and water properties of the mixed layer (i.e., high oxygen, low stratification, and $T / S$ anomalies to the ambient thermocline water). The water parcel we observe has the same properties as the cyclonic eddy mixed layer, but with the opposite sign of vorticity; from this we can infer that the parcel gained anticyclonic vorticity as it subducted (Fig. 6d). If PV is conserved, then the generation of anticyclonic vorticity can occur via vortex squashing (Spall 1995), or by differential vertical motions that drive vortex tilting of the horizontal vorticity associated with the alongfront vertical shear (Thomas 2008; Holmes et al. 2014). The subducting water parcel in our observations bears a striking resemblance to the model results of Thomas (2008, their Fig. 5). The generation of a coherent ITE is not guaranteed to occur for all subducting water parcels because mesoscale straining can disrupt the process by shearing apart the nascent subducting water parcel in elongated ribbons of low PV (see Thomas (2008), their Fig. 4). This may be the case here, but we cannot tell from our transient viewpoint.

There are several mechanisms that can drive frontal subduction of surface water into the thermocline. In the idealized simulations of Spall (1995) and Thomas (2008), it is baroclinic instability of the frontal jet that drives vertical circulation. As the jet meanders and generates eddies, it generates confluent (divergent) flow associated with the downstream (upstream) side of the meander crests, that compresses (expands) the horizontal density gradient. The alongfront velocity accelerates (decelerates) to remain in thermal wind balance, which is compensated for by an eddy overturning cell, leading to downwelling on the denser side and upwelling on the lighter side. However, Spall (1997) showed that when the front is subjected to a large-scale deformation field, the subduction rate is dominated by the resulting frontal ASC rather than time-dependent upwelling/downwelling associated with meandering. More recently, Brannigan et al. (2017) showed in an idealized model that subduction only existed in their highest-resolution model runs $(0.25$ and $2 \mathrm{~km}$, and not $4 \mathrm{~km}$ ), and was directly related to submesoscale instabilities.

From the observations alone, we cannot state conclusively which mechanism is driving the subduction, or if different mechanisms are occurring simultaneously (Spall 1997). However, given the large-scale strain observed, we expect that strain-induced frontogenesis and the resultant ASC plays a central role. Vertical velocity scales as $W \sim \operatorname{Ro} \delta U$, where Ro is the Rossby number $(\zeta / f), \delta$ is the ratio of depth to length scales $(D / L)$, and $U$ is the characteristic velocity (Mahadevan 2016). 


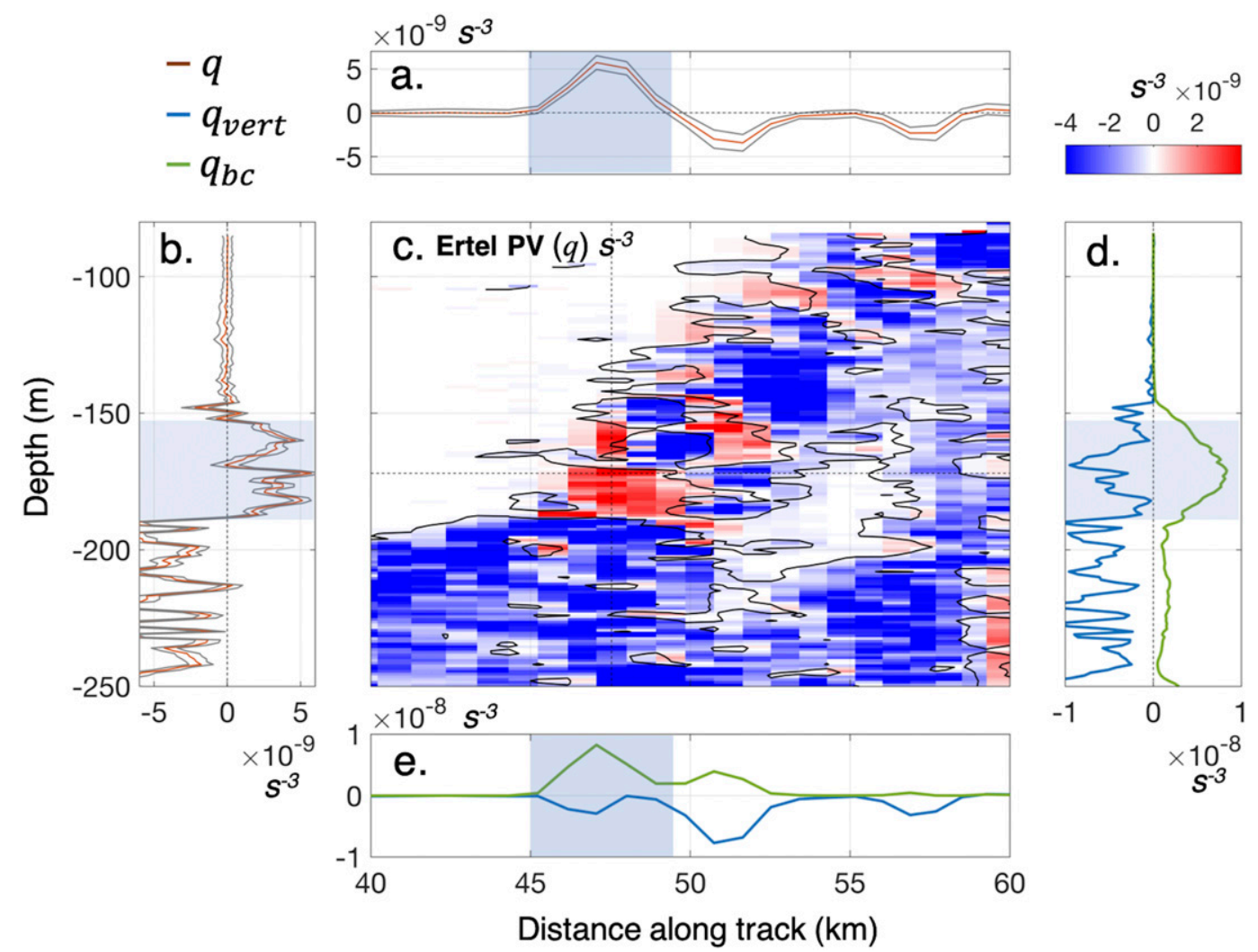

FIG. 8. (a),(b) A 1D profile of PV in distance and depth, respectively. Blue lines denote the confidence intervals. (c) A zoom-in of Ertel PV $q$, the region denoted by the black box in Fig. 7c. Line contours represent the mixed layer $\mathrm{PV}=5 \times 10^{-10} \mathrm{~s}^{-3}$. (d),(e) $1 \mathrm{D}$ profiles of $q_{\mathrm{bc}}$ (green line) and $q_{\mathrm{vert}}$ (blue line). The gray shaded bands denote the region of positive $\mathrm{PV}$, which is inherently unstable.

Based on the observations of the water parcel here, $W \sim 250 \mathrm{~m} \mathrm{day}^{-1}$ (for Ro $=1, D=50 \mathrm{~m}, L=15 \mathrm{~km}, U=$ $1 \mathrm{~m} \mathrm{~s}^{-1}$ ), signifying very strong vertical motions associated with the front. Based on asymmetric vorticity distribution, we would expect the vertical velocity to exhibit stronger downwelling velocities over a smaller area in the cyclonic zone, compared with broader, slower upwelling in the anticyclonic zone (Mahadevan and Tandon 2006). Previous studies calculated the Omega equation (e.g., Rudnick 1996), but we have not done so considering the degree of ageostrophy exhibited (Fig. 7b), and that both quasigeostrophic (QG) and surface QG omega equations fail to capture Rossby number $O(1)$ submesoscale dynamics (Mahadevan 2016). In the following sections we show the presence of submesoscale instabilities that may have also played a role in this subduction.

\section{c. Submesoscale instability and atmospheric forcing}

There is a region of positive PV at the base of the front, in close proximity to the subducted parcel (Fig. 7c). Positive PV in the Southern Hemisphere $(f q<0)$ is inherently unstable (Hoskins 1974). A zoomed-in view of the area (Fig. 8) reveals that this positive PV occurs due to a stable but weak $N^{2}$, such that $q_{\text {vert }}$ is weak, and a strong $M^{2}$, indicating the predominance of the baroclinic PV component $q_{\mathrm{bc}}$ in generating $f q<0$ [section 3c(2)]. We calculated PV in both Cartesian and cylindrical coordinates, and found an average percent difference of $9 \%$ [we show PV calculated in cylindrical coordinates, per Eq. (9), in Figs. 7 and 8]. PV with the opposite sign of $f$ due to a strong $M^{2}$ and weak $N^{2}$ signifies the potential for symmetric instability, as opposed to gravitational or inertial instabilities (Thomas et al. 2013). Symmetric instability, also termed slantwise convection (Taylor and Ferrari 2009), produces a slanted overturning cell at the base of the front.

Positive PV can only be created by surface forcing across the isopycnal outcrop and is ephemeral since it initiates instabilities that act to mix it out and return the flow to marginal stability. To investigate the source of positive $\mathrm{PV}$ observed at this front, we consider the atmospheric conditions around this time period (Fig. 4c and the online supplemental material). The air-sea 


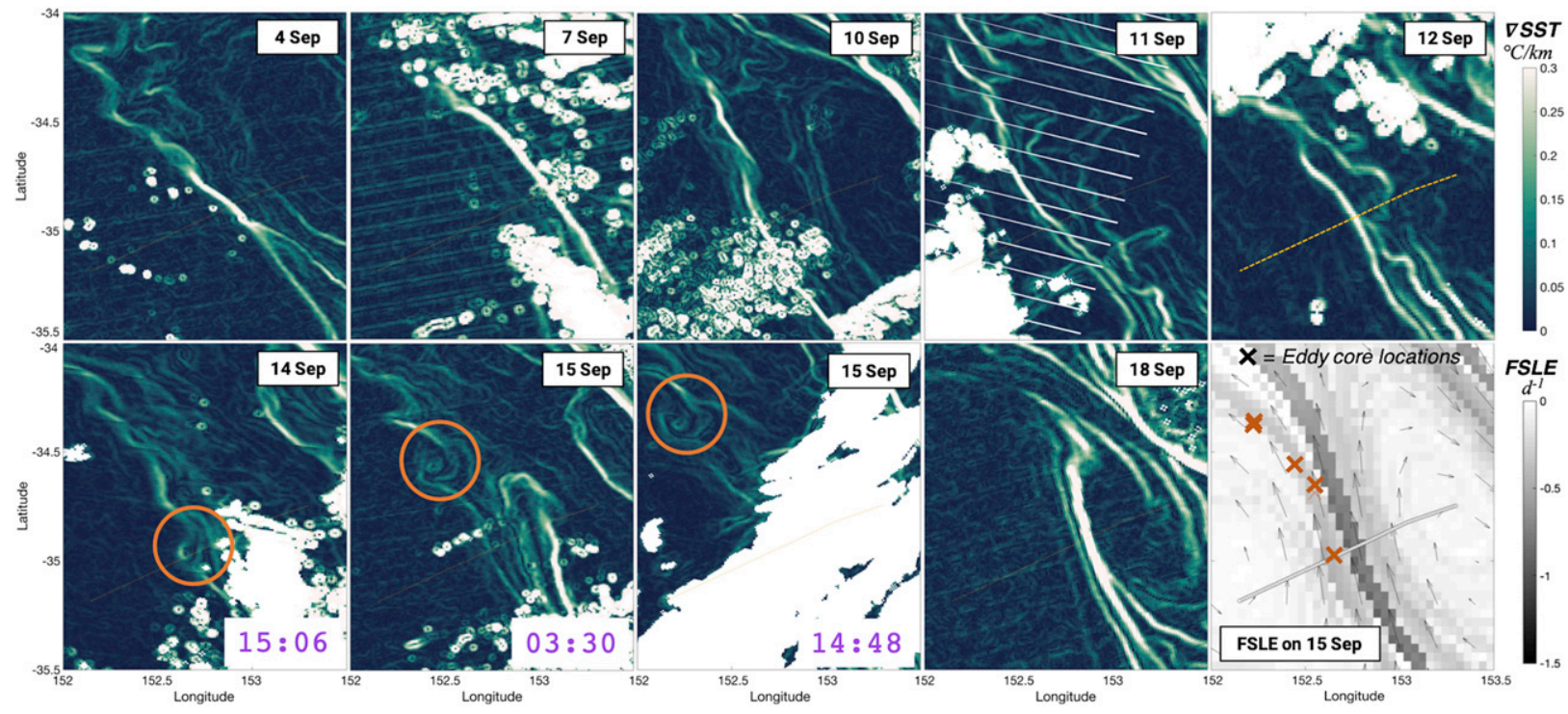

FIG. 9. High-resolution swath measurements of SST from VIIRS. These panels show the progression of the front before, during, and after in situ sampling. Frontal instabilities are observed in satellite imagery on 12-15 Sep, with a wavelength of $\sim 30 \mathrm{~km}$. The color map denotes the horizontal gradient in SST. The data are processed to level L2, with a spatial resolution of $750 \mathrm{~m}$, obtained on 15 Sep 2017 from an ascending swath at approximately 0330 UTC from Suomi-NPP VIIRS. Data source: http://oceandata.sci.gsfc.nasa.gov. The bottomright panel FSLE on 15 Sep shows good agreement to the high-resolution SST frontal images. Red crosses denote centers of the frontal instability highlighted by orange circles on days 14 and 15 Sep.

heat flux, calculated from shipboard meteorological and oceanographic measurements at the front, was destabilizing, exhibiting ocean heat loss of up to $200 \mathrm{~W} \mathrm{~m}^{-2}$ to the atmosphere across the front (Fig. 4c). Such heat fluxes can generate $f q<0$ (Haine and Marshall 1998), and influence frontogenesis and enhance subduction (Yoshikawa et al. 2001). However, when compared to the effect of wind forcing at the front, the heat flux is an order of magnitude smaller. In Fig. 4c, the effect of wind is represented as an Ekman equivalent heat flux $\left(Q_{\mathrm{EK}}\right)$. During in situ sampling of the front, winds were upfront, with a positive $Q_{\mathrm{EK}}$ of $\sim 2500 \mathrm{~W} \mathrm{~m}^{-2}$. Therefore, any water column destabilization via the surface heat flux would have been counteracted by the much larger stabilizing effect of wind forcing.

However, preceding the period of in situ sampling, the wind was downfront (between 8 and 10 September; see supplemental material). Without recourse to additional observations, we can only speculate that this wind forcing may have generated the positive PV we observed on the 12 September, which could be a remnant of a larger region of positive PV that subsequently mixed out. The PV we observed was at the base of the front, furthest from the influence of stabilizing wind. Indeed, the isopycnals at the base are more vertical, while higher in the water column they are more tilted as would be expected from upfront winds. Mahadevan (2016) note it can take several inertial periods to mix out positive PV. Our observations are taken just over two inertial periods after downfront winds stopped (inertial period at $35^{\circ} \mathrm{S}$ is $\sim 21 \mathrm{~h}$ ). Taylor and Ferrari (2009) note the existence of a "fossil remnant mode" of symmetric instability of longer wavelength that persists after the most-unstable mode has mostly driven PV back to zero. We see most of the front is tilting toward restratification; it is only at the base where the front is still vertical and characterized by strong $M^{2}$ and weak $N^{2}$.

\section{d. Baroclinic instability}

Satellite imagery shows the presence of cyclonic eddies along the front 2 days later, on 14-15 September (Fig. 9), with length scales of $\sim 15 \mathrm{~km}$ (unstable wavelength of $\sim 30 \mathrm{~km}$ ). The submesoscale horizontal length scale can be expressed in terms of the horizontal or vertical buoyancy gradients, as $L=M^{2} H / f^{2}$ or $L=N H / f$, respectively (Thomas et al. 2008). Using mean in situ values of the buoyancy gradient at the front $\left(M^{2}=5 \times\right.$ $10^{-7} \mathrm{~s}^{-2}$ and $N^{2}=5 \times 10^{-5} \mathrm{~s}^{-2}$ ) and frontal depth $H=$ $200 \mathrm{~m}$ yields $L=14 \mathrm{~km}(17 \mathrm{~km})$, based on $M^{2}\left(N^{2}\right)$. Thus, we expect these eddies begin as submesoscale instabilities of the front, given that they evolved from a high Ro (and low Richardson) flow (Thomas et al. 2008), and with a length scale on the order of the mixed layer deformation scale. On 13 and 14 September, the wind was strongly downfront and therefore would have had a destabilizing influence (supplemental material). 
a.
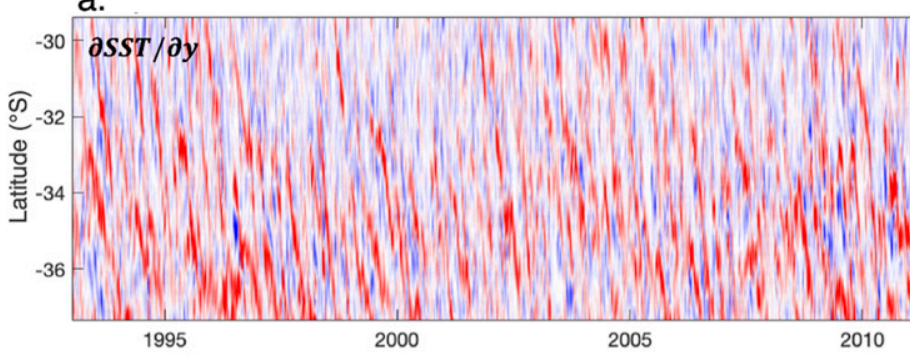

${ }^{\circ} \mathrm{C} / \mathrm{km}$

0.03
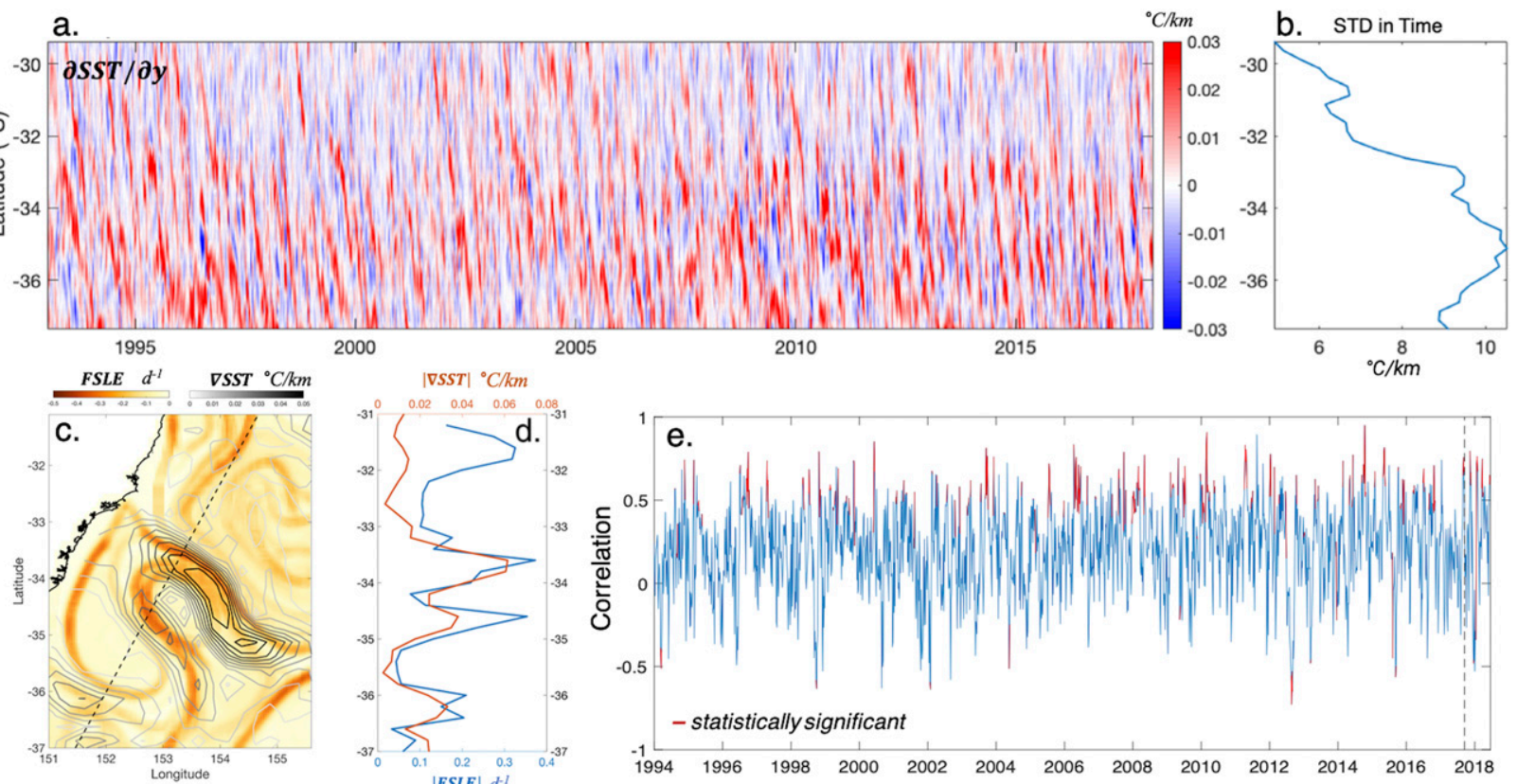

$|\nabla S S T|^{\circ} \mathrm{C} / \mathrm{km}$
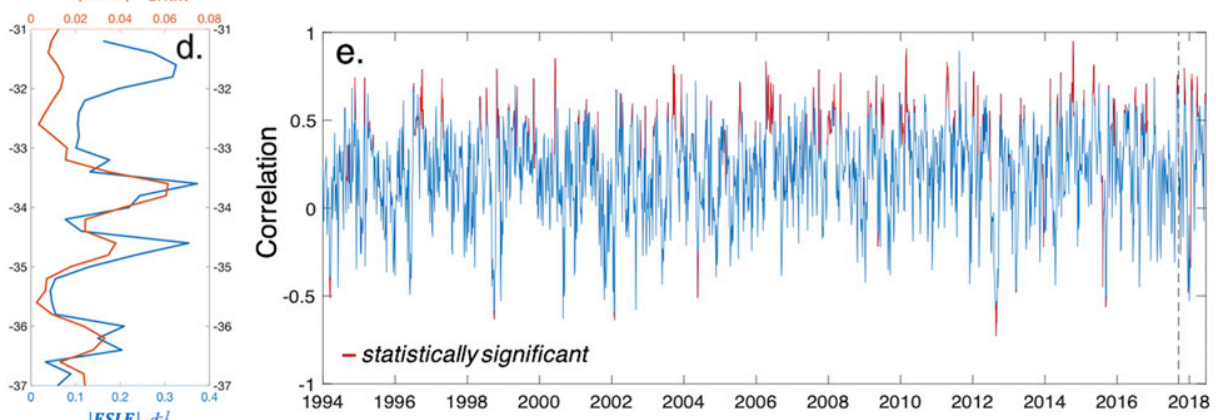

FIG. 10. (a) Satellite-derived time-latitude Hovmöller plots, and (b) time standard deviation of the mesoscale SST gradient reveals strong eddy activity poleward of $\sim 32^{\circ} \mathrm{S}$. (c) FSLE (spatially smoothed) on 4 Sep, superimposed by contour lines of the horizontal SST gradient shows the strong match of these values at frontal zones. The black line denotes the transect over which the Hovmöller and the correlation were taken; (d) Along-transect values of $\mid$ FSLE $\mid$ and $|\nabla S S T|$ as shown in (c); (e) along-transect correlation between $\mid$ FSLE $\mid$ and $|\nabla S S T|$ reveals event-type distribution of periods with high correlation, when anticyclonic eddy shedding events or eddy dipoles are active in the Tasman Sea.

Baroclinic instability can occur as frontal meandering and eddy formation. Several modeling studies have shown how baroclinic instability of a front generates cyclonic frontal eddies at the surface associated with subduction of the denser water (Spall 1995; Manucharyan and Timmermans 2013; see section 5b). However, when a large-scale deformation field is present, instead of the frontal jet devolving into a field of eddies, it remains quasistationary, oscillating between periods of meander growth and decay as the mesoscale frontogenesis counteracts frontolysis by instabilities (Spall 1997). This is a qualitatively similar situation to the frontal jet observed here that is quasistationary and coherent-at times straight (undergoing mesoscale frontogenesis), and at another time meandering (after destabilizing winds). Indeed, Fig. 9 reveals the ongoing evolution of this front, which by 18 September has shifted and strengthened (in temperature gradient), presumably due to frontogenesis driven by the mesoscale strain field of the dipole.

\section{Discussion}

\section{a. A persistent mesoscale eddy dipole pattern}

The front was generated by strain between two counterrotating eddies - a mesoscale eddy dipole — that formed as the anticyclonic EAC retroflection separated from the main EAC branch, and a cyclonic eddy propagated westward in between (section 4, Fig. 2). The eddies of the dipole had distinct water characteristics, and the geostrophic strain between their cores sharpened the existing horizontal gradients (Fig. 3c). A strain field generated by co-interacting mesoscale eddies is known to generate submesoscale gradients of buoyancy (Klein and Lapeyre 2009). This situation preconditioned the flow to frontogenesis, subduction and submesoscale instability (e.g., Haine and Marshall 1998). To investigate how typical the eddy dipole structure is, we surveyed 25 years of satellite imagery in the region. We calculate the SST gradient along a transect that bisects the dipole ( $\partial \mathrm{SST} / \partial y$, where $y$ is the along-transect distance; see Fig. 10). The SST gradient emphasizes the location of fronts between warm and cold water masses and can be used as a proxy to detect horizontal density gradients. Such mesoscale density gradients have been shown in a high-resolution model to be highly correlated with submesoscale vertical velocity (Rosso et al. 2015). An eddy dipole will produce an alternating positivenegative pattern in $\partial \mathrm{SST} / \partial y$. Poleward propagating dipoles are evident in a time-latitude Hovmöller plot, characterized by downward slopes of alternating positivenegative bands (Fig. 10a). There is also a clear distinction 
a.

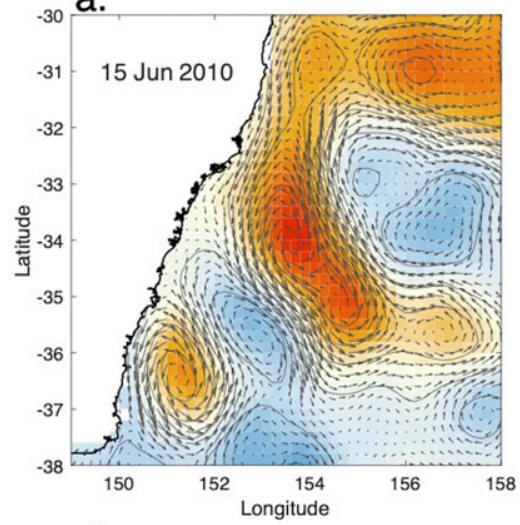

b.

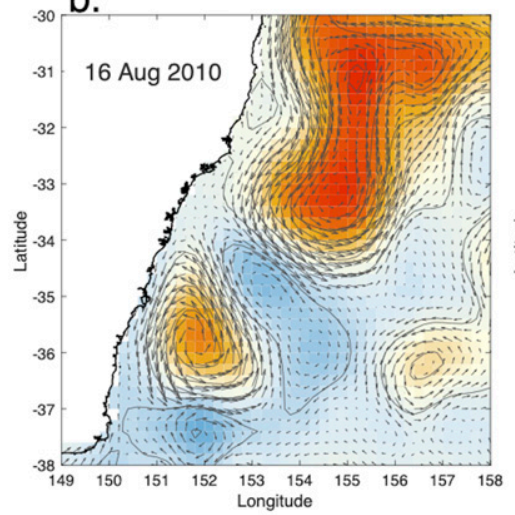

C.

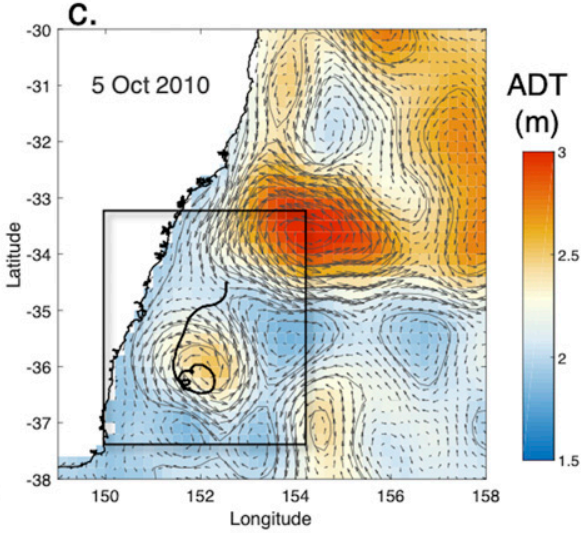

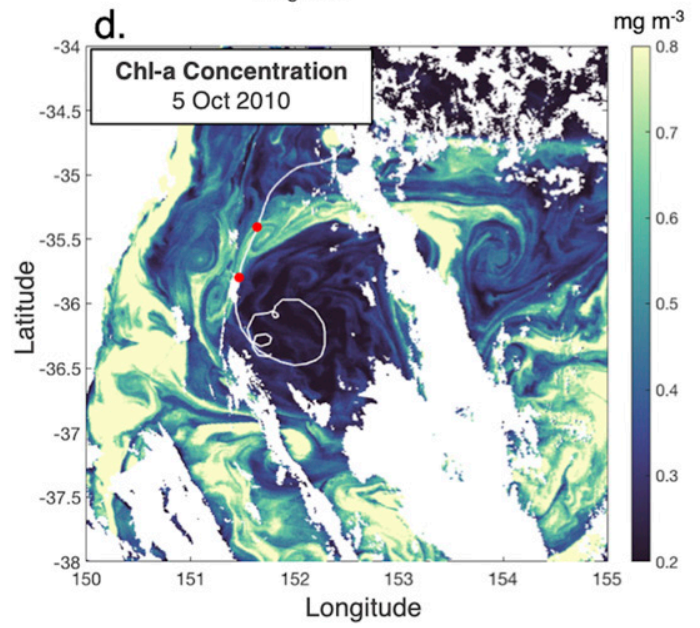

e.

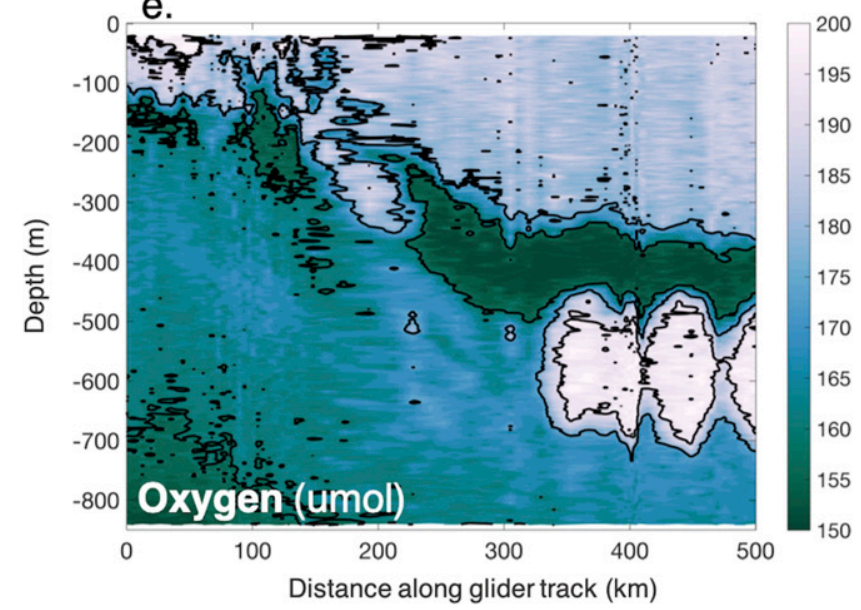

FIG. 11. The anomalous submesoscale lens observed by BR12. ADT maps superimposed with geostrophic currents on (a) 15 Jun 2010 , (b) 16 Aug 2010, and (c) 5 Oct 2010, showing the evolution and persistence of the mesoscale anticyclone. (d) Chlorophyll a concentration from the OC3 algorithm $\left(\mathrm{mg} \mathrm{m}^{-3}\right)$ and (e) glider measurements of oxygen along the track denoted by the black line in (c) and white line in (d). A subducting tongue of high oxygen water is evident at the periphery of the anticyclone-the glider sampling of this tongue feature is denoted by the red stop/start circles in (d).

of flow characteristics upstream and downstream of the mean EAC separation. Poleward of approximately $33^{\circ} \mathrm{S}$, there is significantly higher variance due to the larger eddy magnitudes, associated with eddy avenue (Everett et al. 2012), and the characteristic positive-negative banding from eddy dipoles. The horizontal gradient of SST is correlated with the FSLE field (Figs. 10c-e), which we use to diagnose the time-integrated effect of mesoscale strain, and is associated with large buoyancy gradients (e.g., Siegelman et al. 2020). For the dipole we sampled, the SST gradient and FSLE field correlate along the transect $(r=$ 0.75 ), as both metrics exhibit extrema at the frontal locations between the EAC and dipole eddies. Along-transect correlation over the 25 years of satellite imagery exhibits an event-type pattern, with short periods (days to weeks) of high correlation between the two fields when strong fronts are present in the region.

The persistence of fronts in this region invokes a pattern of recurrent competition between the destabilizing influence of mesoscale straining - which increases available potential energy - and the stabilizing restratification that occurs through rapid frontogenesis and atmospheric buoyancy fluxes that drive instabilities. Such competing forces lead to periods of frontal meandering and submesoscale instability, and periods when the front is straighter (e.g., Fig. 9) (Spall 1997).

\section{b. Submesoscale lenses of anomalous water in the Tasman Sea}

Results presented here may explain the generation mechanism of anomalous submesoscale lenses previously observed in the Tasman Sea (BR12) (Fig. 11). Brannigan et al. (2017) hypothesized that the lenses observed by BR12 were formed by submesoscale instabilities at the surface. We present direct measurements of submesoscale features along an ocean front that lead to the subduction of surface water into the thermocline of an anticyclonic eddy. BR12 highlight that all observed 
lenses were within anticyclonic eddies. This agrees with the intrathermocline eddy generation mechanism; at a front between a warm and cold core eddy, the colder, denser water subducts beneath the relatively lighter anticyclonic eddy. The lifespan of these dipoles is on the order of weeks to months, so the potential for atmospheric forced frontal instabilities and subduction is high.

During the same cruise we observed an anomalous water lens at $600-\mathrm{m}$ depth in the anticyclonic eddy, revealed by CTD measurements of oxygen, temperature, and salinity (supplemental material). The lens had higher oxygen content than ambient water, and higher salinity and temperature. While it is difficult to discern its size based on seven scattered CTD casts, it was not large enough to be sampled by all-only three sampled the feature-so it probably has a horizontal scale less than $50 \mathrm{~km}$, and vertical scale of $\sim 200 \mathrm{~m}$. This closely matches the BR12 lenses of $\sim 40 \mathrm{~km}$ and $\sim 200 \mathrm{~m}$.

Bass Strait water (Fig. 1a) has been shown to flow northward into the Tasman Sea and move along the shelf for up to $200 \mathrm{~km}$ (BR12), during which time there are many opportunities for it to interact with anticyclonic eddies shed from the EAC. Shelf-deep ocean interaction of this type has been documented in the Mid-Atlantic Bight; Gulf Stream anticyclonic eddies come into contact with shelf water, which instigates frontogenesis and subduction (Zhang and Partida 2018). The submesoscale lenses observed by BR12 had water properties matching Bass Strait. The cold core eddy sampled in September 2017 originated from offshore in the Tasman Sea, so was unlikely to contain Bass Strait water. Conversely, the BR12 mesoscale anticyclonic eddy that contained the lens was a persistent feature close to the shelf throughout 2010, so had ample opportunity to interact with shelf water (Fig. 11).

\section{c. Implications}

In situ measurements reveal the front was susceptible to symmetric instability (SI). This has been demonstrated in other western boundary currents [e.g., in the Gulf Stream, Thomas et al. (2013); in the Kuroshio, D'Asaro et al. (2011)]. Unlike mesoscale baroclinic instability, which leads to an inverse cascade of KE, SI extracts KE from the balanced ocean flow and provides a route for dissipation via small-scale turbulence. Such processes are an important link in the cascade of energy from large scales where it is input to the small-scale where it is dissipated (Molemaker et al. 2010; McWilliams 2016). Observations presented here provide the first empirical evidence that the EAC system is likely to comprise this instability type, which could play an important role in the energy balance of the Tasman Sea ocean circulation.
The strong vertical velocity associated with submesoscale eddy-driven subduction has important implications for the export of biogeochemical tracers (heat, salt, carbon, dissolved gases, etc.) from the mixed layer below the pycnocline (Klein and Lapeyre 2009; Omand et al. 2015; Mahadevan 2016). A recent estimate of particulate organic carbon (POC) export showed that in regions of strong mesoscale eddy activity and seasonal MLD variability, up to 50\% of POC export may occur through localized eddy-driven subduction (Omand et al. 2015). In the Tasman Sea, chlorophyll a concentration is anomalously high south of the EAC (Everett et al. 2014), where mesoscale eddy dipoles energize submesoscale frontal instability and subduction (e.g., Fig. 7c). This coupling suggests submesoscale eddy-driven subduction contributes to both primary productivity and air-sea carbon dioxide exchange.

\section{d. Open questions}

Our analysis is restricted to one high-spatial resolution section of a 3D time-dependent process, so many questions remain. There are several mechanisms that can drive or influence the subduction of surface water, including: baroclinic instability of a frontal jet and resultant eddy overturning cell (e.g., Spall 1995), straindriven frontogenesis and resultant secondary circulation (e.g., Spall 1997), and submesoscale instabilities, such as symmetric instability (Brannigan 2016). To delineate the relative influence of these processes requires more high-spatial resolution and time-dependent observations, which we do not have. Based on available observations (Figs. 3 and 7a) and model evidence (Spall 1997), it seems likely that strain-induced frontogenesis dominated, given the large strain values measured. However, different mechanisms can act simultaneously (McWilliams 2016), and with observational evidence for mixed layer baroclinic instability (Fig. 9) and symmetric instability (Fig. 8) it is possible that each of these physical processes has an influence on the vertical exchange of water at this front. More questions generated by our observations-but which require numerical models to answer-include: What is the relationship between $f q<0$ and ITE formation? What is the mechanism by which an ITE formed at an upper-ocean front moves down to depths of $\sim 600 \mathrm{~m}$ ? How does variability in wind speed and direction effect the stability of a front in the presence of mesoscale strain and submesoscale instabilities?

\section{Summary}

In situ measurements at a strong upper-ocean front reveal the existence of submesoscale variability embedded within the mesoscale circulation, south of the EAC 
separation zone. This front appeared to be undergoing strain-induced frontogenesis and was associated with subduction of surface water beneath the mixed layer. The subducting water parcel had low PV, high oxygen, and anticyclonic vorticity, providing observational evidence for the formation of an intrathermocline eddy at an upper-ocean front, as predicted by idealized numerical simulations (Spall 1995; Thomas 2008). At the base of the front, measurements suggest the flow was susceptible to symmetric instability (with $f q<0$ ) due to a very large horizontal buoyancy gradient with a weak but stable vertical buoyancy gradient. We postulate that mesoscale frontogenesis preconditioned the flow to SI, and subsequent downfront winds destabilized the flow, injecting positive PV into the frontal outcrop. Two days after the front was sampled, cloud-free satellite imagery reveals beautiful submesoscale eddies along the front, with a length scale of $\sim 15 \mathrm{~km}$ (Fig. 9).

The frontal subduction of surface water observed here may explain the existence of anomalous submesoscale lenses observed by BR12 at $\sim 600$-m depth in the cores of several anticyclonic eddies. These lenses appear to be relatively common, since we identified a similar feature in the core of the anticyclonic eddy we sampled (supplemental material). Twenty-five years of satellite imagery reveals the existence of strong mesoscale strain coupled with strong temperature fronts in this region and indicates that the conditions which led to frontal subduction observed here are a persistent feature. Our findings suggest that the energetic mesoscale eddy field south of the EAC separation zone is a hotspot for submesoscale instability and subduction, and generate questions about the relationship between submesoscale and mesoscale circulations, their space-time variability, net impact on the export of surface water into the ocean interior, and influence on biological productivity.

Acknowledgments. We heartily thank the scientists, Australian Marine National Facility staff and crew of the $\mathrm{R} / \mathrm{V}$ Investigator who made the voyage a success, under the guidance of chief scientist Iain Suthers, master John Highton, and voyage manager Don McKenzie. Special thanks to Paulina Cetina-Heredia, Carlos Rocha, and Eduardo Queiroz for their vital role in planning the instrument deployment, and Matt Boyd, Karl Malakoff, Jason Fazey, Sven Gastauer, and Kendal Sherrin for technical support and making the $2 \mathrm{am}-2 \mathrm{pm}$ shift so much fun. All data collected on the cruise are available through the Australian Ocean Data Network (www.aodn.org.au). The SSALTO/DUACS altimeter products were produced and distributed by the Copernicus Marine and Environment Monitoring Service (http://www.marine.copernicus.eu), the FSLE were provided in collaboration with LOcean and $\mathrm{CTOH}$ and distributed by Aviso+ (https://www.aviso.altimetry.fr/) with support from CNES. Ocean color and SST imagery was produced by NASA's Ocean Biology Processing Group (https://oceandata.sci.gsfc.nasa.gov/). We make use of "cmocean" colorbars developed by Kristen Thyng, and "brewermap" colorbars developed by Cynthia Brewer and colleagues. This research was partially supported by an Australian Research Council Linkage Project Grant to MR (LP150100064). We are thankful to the two reviewers whose insightful feedback helped improve the quality this manuscript.

\section{REFERENCES}

Adams, K. A., P. Hosegood, J. R. Taylor, J. B. Sallée, S. Bachman, R. Torres, and M. Stamper, 2017: Frontal circulation and submesoscale variability during the formation of a Southern Ocean mesoscale eddy. J. Phys. Oceanogr., 47, 1737-1753, https://doi.org/10.1175/JPO-D-16-0266.1.

Archer, M. R., L. K. Shay, B. Jaimes, and J. Martinez-Pedraja, 2015: Observing frontal instabilities of the Florida Current using high frequency radar. Coastal Ocean Observing Systems, Y. Liu, H. Kerkering, and R. H. Weisberg, Eds., Elsevier, 179-208, https://doi.org/10.1016/B978-0-12-8020227.00011-0.

— M. Roughan, S. R. Keating, and A. Schaeffer, 2017: On the variability of the East Australian Current: Jet structure, meandering, and influence on shelf circulation. J. Geophys. Res. Oceans, 122, 8464-8481, https://doi.org/10.1002/2017JC013097.

_ , S. R. Keating, M. Roughan, W. E. Johns, R. Lumkpin, F. Beron-Vera, and L. K. Shay, 2018: The kinematic similarity of two western boundary currents revealed by sustained highresolution observations. Geophys. Res. Lett., 45, 6176-6185, https://doi.org/10.1029/2018GL078429.

Baird, M. E., and K. R. Ridgway, 2012: The southward transport of sub-mesoscale lenses of Bass Strait Water in the centre of anticyclonic mesoscale eddies. Geophys. Res. Lett., 39, L02603, https://doi.org/10.1029/2011GL050643.

Boccaletti, G., R. Ferrari, and B. Fox-Kemper, 2007: Mixed layer instabilities and restratification. J. Phys. Oceanogr., 37, 2228 2250, https://doi.org/10.1175/JPO3101.1.

Brannigan, L., 2016: Intense submesoscale upwelling in anticyclonic eddies. Geophys. Res. Lett., 43, 3360-3369, https:// doi.org/10.1002/2016GL067926.

_ D. P. Marshall, A. C. Naveira Garabato, A. G. Nurser, and J. Kaiser, 2017: Submesoscale instabilities in mesoscale eddies. J. Phys. Oceanogr., 47, 3061-3085, https://doi.org/10.1175/ JPO-D-16-0178.1.

Bull, C. Y. S., A. E. Kiss, N. C. Jourdain, M. H. England, and E. van Sebille, 2017: Wind forced variability in eddy formation, eddy shedding, and the separation of the East Australian Current. J. Geophys. Res. Oceans, 122, 9980-9998, https://doi.org/ 10.1002/2017JC013311.

Callies, J., R. Ferrari, J. M. Klymak, and J. Gula, 2015: Seasonality in submesoscale turbulence. Nat. Commun., 6, 6862, https:// doi.org/10.1038/ncomms7862.

Capet, X., J. C. McWilliams, M. J. Molemaker, and A. F. Shchepetkin, 2008: Mesoscale to submesoscale transition in the California Current System. Part I: Flow structure, eddy flux, and observational tests. J. Phys. Oceanogr., 38, 29-43, https://doi.org/10.1175/2007JPO3671.1. 
Cetina-Heredia, P., M. Roughan, E. van Sebille, and M. A. Coleman, 2014: Long-term trends in the East Australian Current separation latitude and eddy driven transport. J. Geophys. Res. Oceans, 119, 4351-4366, https://doi.org/ 10.1002/2014JC010071.

Chereskin, T. K., C. B. Rocha, S. T. Gille, D. Menemenlis, and M. Passaro, 2019: Characterizing the transition from balanced to unbalanced motions in the southern California Current J. Geophys. Res. Oceans, 124, 2088-2109, https://doi.org/ 10.1029/2018JC014583.

D'Asaro, E. A., 1988: Generation of submesoscale vortices: A new mechanism. J. Geophys. Res., 93, 6685-6693, https://doi.org/ 10.1029/JC093iC06p06685.

_ C. Lee, L. Rainville, R. Harcourt, and L. Thomas, 2011: Enhanced turbulence and energy dissipation at ocean fronts Science, 332, 318-322, https://doi.org/10.1126/science.1201515.

d'Ovidio, F., V. Fernández, E. Hernández-García, and C. López, 2004: Mixing structures in the Mediterranean Sea from finitesize Lyapunov exponents. Geophys. Res. Lett., 31, L17203, https://doi.org/10.1029/2004GL020328.

Dugan, J. P., R. P. Mied, P. C. Mignerey, and A. F. Schuetz, 1982: Compact, intrathermocline eddies in the Sargasso sea. J. Geophys. Res., 87, 385-393, https://doi.org/10.1029/JC087iC01p00385.

Everett, J. D., M. E. Baird, P. R. Oke, and I. M. Suthers, 2012: An avenue of eddies: Quantifying the biophysical properties of mesoscale eddies in the Tasman Sea. Geophys. Res. Lett., 39, L16608, https://doi.org/10.1029/2012GL053091.

_ - — , M. Roughan, I. M. Suthers, and A. M. Doblin, 2014: Relative impact of seasonal and oceanographic drivers on surface chlorophyll a along a Western Boundary Current. Prog. Oceanogr., 120, 340-351, https://doi.org/10.1016/ j.pocean.2013.10.016.

_ , H. S. Macdonald, M. E. Baird, J. Humphries, M. Roughan, and I. M. Suthers, 2015: Cyclonic entrainment of preconditioned shelf waters into a Frontal Eddy. J. Geophys. Res. Oceans, 120, 677-691, https://doi.org/10.1002/2014JC010301.

Fairall, C. W., E. F. Bradley, D. P. Rogers, J. B. Edson, and G. S. Young, 1996: Bulk parameterization of air-sea fluxes for tropical ocean-global atmosphere coupled-ocean atmosphere response experiment. J. Geophys. Res., 101, 3747-3764, https://doi.org/10.1029/95JC03205.

Fischer, J., P. Brandt, M. Dengler, M. Müller, and D. Symonds, 2003: Surveying the upper ocean with the Ocean Surveyor: A new phased array Doppler current profiler. J. Atmos. Oceanic Technol., 20, 742-751, https://doi.org/10.1175/1520-0426(2003) $20<742$ :STUOWT $>2.0 . \mathrm{CO} ; 2$.

Flament, P., L. Armi, and L. Washburn, 1985: The evolving structure of an upwelling filament. J. Geophys. Res., 90, 11 765-11 778, https://doi.org/10.1029/JC090iC06p11765.

Fox-Kemper, B., R. Ferrari, and R. Hallberg, 2008: Parameterization of mixed layer eddies. Part I: Theory and diagnosis. J. Phys. Oceanogr., 38, 1145-1165, https://doi.org/10.1175/2007JPO3792.1.

Godfrey, J. S., G. R. Cresswell, T. J. Golding, A. F. Pearce, and R. Boyd, 1980: The separation of the east Australian current. J. Phys. Oceanogr., 10, 430-440, https://doi.org/10.1175/15200485(1980)010<0430:TSOTEA $>2.0 . \mathrm{CO} ; 2$.

Gula, J., T. M. Blacic, and R. E. Todd, 2019: Submesoscale coherent vortices in the Gulf Stream. Geophys. Res. Lett., 46, 2704-2714, https://doi.org/10.1029/2019GL081919.

Haine, T. W., and J. Marshall, 1998: Gravitational, symmetric, and baroclinic instability of the ocean mixed layer. J. Phys. Oceanogr., 28, 634-658, https://doi.org/10.1175/1520-0485(1998)028<0634: GSABIO $>2.0 . \mathrm{CO} ; 2$
Holmes, R. M., L. N. Thomas, L. Thompson, and D. Darr, 2014: Potential vorticity dynamics of tropical instability vortices. $J$. Phys. Oceanogr., 44, 995-1011, https://doi.org/10.1175/JPO-D-13-0157.1.

Hoskins, B. J., 1974: The role of potential vorticity in symmetric stability and instability. Quart. J. Roy. Meteor. Soc., 100, 480 482, https://doi.org/10.1002/qj.49710042520.

_- 1982: The mathematical theory of frontogenesis. Annu. Rev. Fluid Mech., 14, 131-151, https://doi.org/10.1146/ annurev.fl.14.010182.001023.

Jungclaus, J. H., 1999: A three-dimensional simulation of the formation of anticyclonic lenses (meddies) by the instability of an intermediate depth boundary current. J. Phys. Oceanogr., 29, 1579-1598, https://doi.org/10.1175/1520-0485(1999)029<1579: ATDSOT $>2.0 . \mathrm{CO} ; 2$

Kim, S. Y., and Coauthors, 2011: Mapping the US west coast surface circulation: A multiyear analysis of high-frequency radar observations. J. Geophys. Res., 116, C03011, https://doi.org/ 10.1029/2010JC006669.

Klein, P., and G. Lapeyre, 2009: The oceanic vertical pump induced by mesoscale and submesoscale turbulence. Annu. Rev. Mar. Sci., 1, 351-375, https://doi.org/10.1146/annurev.marine.010908.163704.

Klymak, J. M., and Coauthors, 2016: Submesoscale streamers exchange water on the north wall of the Gulf Stream. Geophys. Res. Lett., 43, 1226-1233, https://doi.org/10.1002/ 2015GL067152.

Kostianoy, A., and I. Belkin, 1989: A survey of observations on intrathermocline eddies in the world ocean. Mesoscale/Synoptic Coherent structures in Geophysical Turbulence, J. Nihoul and B. Jamart, Eds., Elsevier Oceanography Series, Vol. 50, Elsevier, 821-841, https://doi.org/10.1016/S0422-9894(08)70223-X.

Lee, C. M., L. N. Thomas, and Y. Yoshikawa, 2006: Intermediate water formation at the Japan/East Sea subpolar front. Oceanography, 19, 110-121, https://doi.org/10.5670/oceanog.2006.48.

Macdonald, H. S., M. Roughan, M. E. Baird, and J. Wilkin, 2013: A numerical modeling study of the East Australian Current encircling and overwashing a warm-core eddy. J. Geophys. Res. Oceans, 118, 301-315, https://doi.org/10.1029/2012JC008386.

Mahadevan, A., 2016: The impact of submesoscale physics on primary productivity of plankton. Annu. Rev. Mar. Sci., 8, 161184, https://doi.org/10.1146/annurev-marine-010814-015912. , and A. Tandon, 2006: An analysis of mechanisms for submesoscale vertical motion at ocean fronts. Ocean Modell., 14, 241-256, https://doi.org/10.1016/j.ocemod.2006.05.006.

Malan, N., and Coauthors, 2020: Eddy-driven cross-shelf transport in the East Australian Current separation zone. J. Geophys. Res. Oceans, 125, e2019JC015613, https://doi.org/10.1029/ 2019JC015613.

Mantovanelli, A., S. Keating, L. R. Wyatt, M. Roughan, and A. Schaeffer, 2017: Lagrangian and Eulerian characterization of two counter-rotating submesoscale eddies in a western boundary current. J. Geophys. Res. Oceans, 122, 4902-4921, https://doi.org/10.1002/2016JC011968.

Manucharyan, G. E., and M. L. Timmermans, 2013: Generation and separation of mesoscale eddies from surface ocean fronts. J. Phys. Oceanogr., 43, 2545-2562, https://doi.org/10.1175/ JPO-D-13-094.1.

McDougall, T. J., and P. M. Barker, 2011: Getting started with TEOS-10 and the Gibbs Seawater (GSW) Oceanographic Toolbox. SCOR/IAPSO WG127, 28 pp., http://www.teos10.org/pubs/Getting_Started.pdf.

McWilliams, J. C., 1985: Submesoscale, coherent vortices in the ocean. Rev. Geophys., 23, 165-182, https://doi.org/10.1029/ RG023i002p00165. 
- 2016: Submesoscale currents in the ocean. Proc. Roy. Soc., 472A, 20160117, https://doi.org/10.1098/rspa.2016.0117.

Molemaker, M., J. McWilliams, and X. Capet, 2010: Balanced and unbalanced routes to dissipation in an equilibrated Eady flow. J. Fluid Mech., 654, 35-63, https://doi.org/10.1017/ S0022112009993272.

$\longrightarrow,-$, and W. K. Dewar, 2015: Submesoscale instability and generation of mesoscale anticyclones near a separation of the California Undercurrent. J. Phys. Oceanogr., 45, 613-629, https://doi.org/10.1175/JPO-D-13-0225.1.

Munk, W., L. Armi, K. Fischer, and F. Zachariasen, 2000: Spirals on the sea. Proc. Roy. Soc. London, 456A, 1217-1280, https:// doi.org/10.1098/rspa.2000.0560.

Oke, P. R., and Coauthors, 2019: Revisiting the circulation of the East Australian Current: Its path, separation, and eddy field. Prog. Oceanogr., 176, 102139, https://doi.org/10.1016/ j.pocean.2019.102139.

Omand, M. M., E. A. D'Asaro, C. M. Lee, M. J. Perry, N. Briggs, I. Cetinić, and A. Mahadevan, 2015: Eddy-driven subduction exports particulate organic carbon from the spring bloom. Science, 348, 222-225, https://doi.org/10.1126/science.1260062.

Poje, A. C., and Coauthors, 2014: Submesoscale dispersion in the vicinity of the Deepwater Horizon spill. Proc. Natl. Acad. Sci. USA, 111, 12 693-12 698, https://doi.org/10.1073/pnas.1402452111.

Pollard, R. T., and L. A. Regier, 1992: Vorticity and vertical circulation at an ocean front. J. Phys. Oceanogr., 22, 609-625, https://doi.org/10.1175/1520-0485(1992)022<0609:VAVCAA $>$ 2.0.CO;2.

Pujol, M. I., Y. Faugère, G. Taburet, S. Dupuy, C. Pelloquin, M. Ablain, and N. Picot, 2016: DUACS DT2014: The new multi-mission altimeter data set reprocessed over 20 years. Ocean Sci., 12, 1067-1090, https://doi.org/10.5194/os-12-10672016.

Qiu, B., T. Nakano, S. Chen, and P. Klein, 2017: Submesoscale transition from geostrophic flows to internal waves in the northwestern Pacific upper ocean. Nat. Commun., 8, 14055, https://doi.org/10.1038/ncomms14055.

Rocha, C. B., S. T. Gille, T. K. Chereskin, and D. Menemenlis, 2016: Seasonality of submesoscale dynamics in the Kuroshio extension. Geophys. Res. Lett., 43, 11304-11311, https:// doi.org/10.1002/2016GL071349.

Rosso, I., A. M. Hogg, A. E. Kiss, and B. Gayen, 2015: Topographic influence on submesoscale dynamics in the Southern Ocean. Geophys. Res. Lett., 42, 1139-1147, https://doi.org/10.1002/ 2014GL062720.

Roughan, M., S. R. Keating, A. Schaeffer, P. Cetina Heredia, C. Rocha, D. Griffin, R. Robertson, and I. M. Suthers, 2017: A tale of two eddies: The biophysical characteristics of two contrasting cyclonic eddies in the East Australian Current System. J. Geophys. Res. Oceans, 122, 2494-2518, https:// doi.org/10.1002/2016JC012241.

Rudnick, D. L., 1996: Intensive surveys of the Azores front: 2. Inferring the geostrophic and vertical velocity fields. J. Geophys. Res., 101, 16291-16303, https://doi.org/10.1029/ 96JC01144.

Sasaki, H., P. Klein, B. Qiu, and Y. Sasai, 2014: Impact of oceanicscale interactions on the seasonal modulation of ocean dynamics by the atmosphere. Nat. Commun., 5, 5636, https:// doi.org/10.1038/ncomms6636.

Schaeffer, A., A. Gramoulle, M. Roughan, and A. Mantovanelli, 2017: Characterizing frontal eddies along the East Australian Current from HF radar observations. J. Geophys. Res. Oceans, 122, 3964-3980, https://doi.org/10.1002/2016JC012171.
Shakespeare, C. J., 2016: Curved density fronts: Cyclogeostrophic adjustment and frontogenesis. J. Phys. Oceanogr., 46, 3193 3207, https://doi.org/10.1175/JPO-D-16-0137.1.

— , and J. R. Taylor, 2014: The spontaneous generation of inertiagravity waves during frontogenesis forced by large strain: Theory. J. Fluid Mech., 757, 817-853, https://doi.org/10.1017/jfm.2014.514.

Shcherbina, A. Y., E. A. D'Asaro, C. M. Lee, J. M. Klymak, M. J. Molemaker, and J. C. McWilliams, 2013: Statistics of vertical vorticity, divergence, and strain in a developed submesoscale turbulence field. Geophys. Res. Lett., 40, 4706-4711, https:// doi.org/10.1002/grl.50919

, and Coauthors, 2015: The LatMix summer campaign: Submesoscale stirring in the upper ocean. Bull. Amer. Meteor. Soc., 96, 1257-1279, https://doi.org/10.1175/BAMS-D-14-00015.1.

Siegelman, L., P. Klein, P. Riviere, A. F. Thompson, H. S. Torres, M. Flexas, and D. Menemenlis, 2020: Enhanced upward heat transport at deep submesoscale ocean fronts. Nat. Geosci., 13, 50-55, https://doi.org/10.1038/s41561-019-0489-1.

Spall, M. A., 1995: Frontogenesis, subduction, and cross-front exchange at upper ocean fronts. J. Geophys. Res., 100, $2543-$ 2557, https://doi.org/10.1029/94JC02860.

_ 1997: Baroclinic jets in confluent flow. J. Phys. Oceanogr., 27, 1054-1071, https://doi.org/10.1175/1520-0485(1997)027<1054: $\mathrm{BJICF}>2.0 . \mathrm{CO} ; 2$.

Stone, P. H., 1970: On non-geostrophic baroclinic stability: Part II. J. Atmos. Sci., 27, 721-726, https://doi.org/10.1175/15200469(1970)027<0721:ONGBSP $>2.0$. CO;2.

$\mathrm{Su}, \mathrm{Z}$., J. Wang, P. Klein, A. F. Thompson, and D. Menemenlis, 2018: Ocean submesoscales as a key component of the global heat budget. Nat. Commun., 9, 775, https://doi.org/10.1038/ s41467-018-02983-w.

Suthers, I. M., and Coauthors, 2011: The strengthening East Australian Current, its eddies and biological effects-An introduction and overview. Deep-Sea Res. II, 58, 538-546, https://doi.org/10.1016/j.dsr2.2010.09.029.

Taylor, J. R., and R. Ferrari, 2009: On the equilibration of a symmetrically unstable front via a secondary shear instability. J. Fluid Mech., 622, 103-113, https://doi.org/10.1017/S0022112008005272.

Thomas, L. N., 2008: Formation of intrathermocline eddies at ocean fronts by wind-driven destruction of potential vorticity. Dyn. Atmos. Oceans, 45, 252-273, https://doi.org/10.1016/ j.dynatmoce.2008.02.002.

_ , and C. M. Lee, 2005: Intensification of ocean fronts by downfront winds. J. Phys. Oceanogr., 35, 1086-1102, https://doi.org/ 10.1175/JPO2737.1.

— A. Aandon, and A. Mahadevan, 2008: Submesoscale processes and dynamics. Ocean Modeling in an Eddying Regime, Geophys. Monogr., Vol. 177, Amer. Geophys. Union, 17-38, https://doi.org/10.1029/177GM04.

— J. R. Taylor, R. Ferrari, and T. M. Joyce, 2013: Symmetric instability in the Gulf Stream. Deep-Sea Res. II, 91, 96-110, https://doi.org/10.1016/j.dsr2.2013.02.025.

Thompson, A. F., A. Lazar, C. Buckingham, A. C. Naveira Garabato, G. M. Damerell, and K. J. Heywood, 2016: Openocean submesoscale motions: A full seasonal cycle of mixed layer instabilities from gliders. J. Phys. Oceanogr., 46, 12851307, https://doi.org/10.1175/JPO-D-15-0170.1.

Torres, H. S., P. Klein, D. Menemenlis, B. Qiu, Z. Su, J. Wang, S. Chen, and L.-L. Fu, 2018: Partitioning ocean motions into balanced motions and internal gravity waves: A modeling study in anticipation of future space missions. J. Geophys. Res. Oceans, 123, 8084-8105, https://doi.org/ 10.1029/2018JC014438. 
Viglione, G. A., A. F. Thompson, M. M. Flexas, J. Sprintall, and S. Swart, 2018: Abrupt transitions in submesoscale structure in southern Drake Passage: Glider observations and model results. J. Phys. Oceanogr., 48, 2011-2027, https://doi.org/10.1175/JPO-D-17-0192.1.

Wang, D. P., C. N. Flagg, K. Donohue, and H. T. Rossby, 2010: Wavenumber spectrum in the Gulf Stream from shipboard ADCP observations and comparison with altimetry measurements. J. Phys. Oceanogr., 40, 840-844, https://doi.org/ 10.1175/2009JPO4330.1.

Waugh, D. W., and E. R. Abraham, 2008: Stirring in the global surface ocean. Geophys. Res. Lett., 35, L20605, https://doi.org/ 10.1029/2008GL035526.
Yoo, J. G., S. Y. Kim, and H. S. Kim, 2018: Spectral descriptions of submesoscale surface circulation in a coastal region. J. Geophys. Res. Oceans, 123, 4224-4249, https://doi.org/ 10.1029/2016JC012517.

Yoshikawa, Y., K. Akitomo, and T. Awaji, 2001: Formation process of intermediate water in baroclinic current under cooling. J. Geophys. Res., 106, 1033-1051, https://doi.org/ 10.1029/2000JC000226.

Zhang, W. G., and J. Partida, 2018: Frontal subduction of the MidAtlantic Bight shelf water at the onshore edge of a warm-core ring. J. Geophys. Res. Oceans, 123, 7795-7818, https://doi.org/ 10.1029/2018JC013794. 